\title{
Nitrogen dioxide observations from the Geostationary Trace gas and Aerosol Sensor Optimization (GeoTASO) airborne instrument: Retrieval algorithm and measurements during DISCOVER-AQ Texas 2013
}

Caroline R. Nowlan ${ }^{1}$, Xiong Liu ${ }^{1}$, James W. Leitch ${ }^{2}$, Kelly Chance $^{1}$, Gonzalo González Abad ${ }^{1}$, Cheng Liu ${ }^{1, a}$, Peter Zoogman ${ }^{1}$, Joshua Cole ${ }^{2}$, Thomas Delker ${ }^{2}$, William Good ${ }^{2}$, Frank Murcray ${ }^{2}$, Lyle Ruppert ${ }^{2}$, Daniel Soo $^{2}$, Melanie B. Follette-Cook ${ }^{3,4}$, Scott J. Janz ${ }^{4}$, Matthew G. Kowalewski ${ }^{4}$, Christopher P. Loughner ${ }^{4,5}$,

Kenneth E. Pickering ${ }^{4}$, Jay R. Herman ${ }^{6}$, Melinda R. Beaver ${ }^{7}$, Russell W. Long ${ }^{7}$, James J. Szykman ${ }^{7}$, Laura M. Judd ${ }^{8}$, Paul Kelley ${ }^{5,9}$, Winston T. Luke ${ }^{9}$, Xinrong Ren ${ }^{5,9}$, and Jassim A. Al-Saadi ${ }^{10}$

${ }^{1}$ Harvard-Smithsonian Center for Astrophysics, Cambridge, MA 02138, USA

${ }^{2}$ Ball Aerospace \& Technologies Corporation, Boulder, CO 80301, USA

${ }^{3}$ Morgan State University/GESTAR, Baltimore, MD 21251, USA

${ }^{4}$ NASA Goddard Space Flight Center, Greenbelt, MD 20771, USA

${ }^{5}$ University of Maryland, College Park, MD 20742, USA

${ }^{6}$ University of Maryland, Baltimore County, Baltimore, MD 21201, USA

${ }^{7}$ Environmental Protection Agency, Research Triangle Park, NC 27711, USA

${ }^{8}$ University of Houston, Houston, TX 77004, USA

${ }^{9}$ NOAA Air Resources Laboratory, College Park, MD 20740, USA

${ }^{10}$ NASA Langley Research Center, Hampton, VA 23681, USA

${ }^{a}$ now at: University of Science and Technology, Hefei, Anhui, China

Correspondence to: C. R. Nowlan (cnowlan@ cfa.harvard.edu)

Received: 20 November 2015 - Published in Atmos. Meas. Tech. Discuss.: 15 December 2015

Revised: 17 May 2016 - Accepted: 31 May 2016 - Published: 23 June 2016

\begin{abstract}
The Geostationary Trace gas and Aerosol Sensor Optimization (GeoTASO) airborne instrument is a test bed for upcoming air quality satellite instruments that will measure backscattered ultraviolet, visible and near-infrared light from geostationary orbit. GeoTASO flew on the NASA Falcon aircraft in its first intensive field measurement campaign during the Deriving Information on Surface Conditions from Column and Vertically Resolved Observations Relevant to Air Quality (DISCOVER-AQ) Earth Venture Mission over Houston, Texas, in September 2013. Measurements of backscattered solar radiation between 420 and $465 \mathrm{~nm}$ collected on 4 days during the campaign are used to determine slant column amounts of $\mathrm{NO}_{2}$ at $250 \mathrm{~m} \times 250 \mathrm{~m}$ spatial resolution with a fitting precision of $2.2 \times 10^{15}$ molecules $\mathrm{cm}^{-2}$. These slant columns are converted to tropospheric $\mathrm{NO}_{2}$ vertical columns using a radiative transfer model and trace
\end{abstract}

gas profiles from the Community Multiscale Air Quality (CMAQ) model. Total column $\mathrm{NO}_{2}$ from GeoTASO is well correlated with ground-based Pandora observations $(r=$ 0.90 on the most polluted and cloud-free day of measurements and $r=0.74$ overall), with GeoTASO $\mathrm{NO}_{2}$ slightly higher for the most polluted observations. Surface $\mathrm{NO}_{2}$ mixing ratios inferred from GeoTASO using the CMAQ model show good correlation with $\mathrm{NO}_{2}$ measured in situ at the surface during the campaign $(r=0.85) . \mathrm{NO}_{2}$ slant columns from GeoTASO also agree well with preliminary retrievals from the GEO-CAPE Airborne Simulator (GCAS) which flew on the NASA King Air B200 $(r=0.81$, slope $=0.91)$. Enhanced $\mathrm{NO}_{2}$ is resolvable over areas of traffic $\mathrm{NO}_{x}$ emissions and near individual petrochemical facilities. 


\section{Introduction}

The next generation of satellite instruments designed for air quality applications will operate from geostationary orbit, providing measurements of trace gases in the Earth's atmosphere with unprecedented spatial and temporal resolution. These instruments include the upcoming Tropospheric Emissions: Monitoring of POllution (TEMPO) instrument (Chance et al., 2013), which is a component of the NASA decadal survey mission GEOstationary Coastal and Air Pollution Events (GEO-CAPE) (Fishman et al., 2012), the Geostationary Environmental Monitoring Spectrometer (GEMS) (Kim, 2012) and the Sentinel-4 mission (Ingmann et al., 2012), which will focus respectively on North America, East Asia, and Europe and North Africa.

One of the principal trace gas products of these instruments is nitrogen dioxide $\left(\mathrm{NO}_{2}\right)$. Nitrogen oxides $\left(\mathrm{NO}_{x} \equiv\right.$ $\mathrm{NO}+\mathrm{NO}_{2}$ ) play a central role in atmospheric air quality. $\mathrm{NO}_{2}$ is a toxic gas, and $\mathrm{NO}_{x}$ is involved in aerosol production and ozone photochemistry. Globally, the major sources of $\mathrm{NO}_{x}$ are combustion (primarily from transportation and thermal power plants), soils and lightning. In urban areas, sources of $\mathrm{NO}_{x}$ are dominated by transportation and industry, with $\mathrm{NO}_{2}$ showing a strong correlation with total population (Lamsal et al., 2013).

$\mathrm{NO}_{2}$ has relatively strong spectral absorption features in the visible region of the spectrum, which have been exploited over the past 2 decades for remote sensing using measurements of backscattered solar radiation from several instruments on sun-synchronous satellites (Martin et al., 2002; Boersma et al., 2004; Richter et al., 2011; Bucsela et al., 2013). These instruments are the predecessors of the upcoming geostationary air quality instruments.

The Geostationary Trace gas and Aerosol Sensor Optimization (GeoTASO) aircraft instrument (Leitch et al., 2014) has been developed by Ball Aerospace under the NASA Earth Science Technology Office Instrument Incubator Program in support of satellite measurements from geostationary orbit. Originally conceived as a test bed instrument for GEO-CAPE, GeoTASO is now also part of the mission risk reduction for TEMPO and GEMS in both instrument design and retrieval algorithm development.

GeoTASO is able to map the atmosphere in two dimensions (2-D) under the aircraft's flight track. GeoTASO operates as a hyperspectral push broom scanner, where the spectral information is provided by the $y$ dimension of a 2-D charge-coupled device (CCD) array detector, the cross-track spatial dimension is provided by the $x$ dimension of the array and the along-track spatial dimension is provided by the movement of the aircraft in its flight path. Pushbroom scanner measurements are analogous to the type of measurements that will be made by the geostationary satellite instruments, but the satellite instruments will utilize a scan mirror to move the field of view (FOV).
These types of measurements from aircraft are relatively new, with push broom $\mathrm{NO}_{2}$ airborne 2-D measurements reported recently over the Highveld region of South Africa (Heue et al., 2008), Zurich, Switzerland (Popp et al., 2012), northwest Germany (Schönhardt et al., 2015) and Leicester, United Kingdom (Lawrence et al., 2015). General et al. (2014) have also recently reported airborne 2-D observations of volcanic $\mathrm{BrO}$ and $\mathrm{SO}_{2}$ over Mt. Etna, $\mathrm{BrO}$ and $\mathrm{NO}_{2}$ over Alaska and $\mathrm{NO}_{2}$ over Indianapolis using an instrument equipped with a whisk broom scanner for nadir observations and a push broom scanner observing in limb geometry for obtaining vertical information. In addition, the GEO-CAPE Airborne Simulator (GCAS) (Kowalewski and Janz, 2014) is a recently developed push broom sensor which had its first campaign deployment at the same time as GeoTASO.

This paper introduces the GeoTASO instrument and describes algorithm development and the first trace gas retrievals of $\mathrm{NO}_{2}$ from this new instrument. Section 2 describes the GeoTASO optical design and measurement strategy. Section 3 describes the deployment of GeoTASO during the Deriving Information on Surface Conditions from Column and Vertically Resolved Observations Relevant to Air Quality (DISCOVER-AQ) Texas 2013 field campaign and introduces supporting measurements for validation. Section 4 describes the data analysis for GeoTASO observations including calibration and spectral fitting for the retrieval of trace gas amounts. Section 5 presents the first results from GeoTASO and validation using data from other instruments collected during the DISCOVER-AQ campaign. Section 6 summarizes the current status of GeoTASO and presents plans for future data analysis.

\section{GeoTASO instrument}

GeoTASO (Leitch et al., 2014) is a hyperspectral instrument measuring nadir backscattered light in the ultraviolet and visible in two channels at wavelengths 290-400 (UV) and 415$695 \mathrm{~nm}$ (VIS). Table 1 summarizes the main characteristics of the instrument.

\subsection{Spectrometer design}

GeoTASO uses an Offner imaging spectrometer with the optical design shown in Fig. 1. A wide-field telescope with an FOV of about $45^{\circ}$ in the aircraft's cross-track dimension provides light to the spectrometer. After passing through a slit and depolarization assembly, light is reflected and diffracted off mirrors and a grating. A dichroic beam splitter splits the diffracted light into first (VIS channel) and second (UV channel) orders, which are detected by two 2-D CCD detector arrays. Additional UV and VIS blocking filters provide high inband throughput with a $25 \mathrm{~nm}$ wavelength transition region to high level blocking ( $2 \%$ transmission) for out-of-band light within the sensor's wavelength range. The CCD arrays each consist of $1024 \times 1024$ active individual detector pixels. The 
Table 1. GeoTASO instrument characteristics. Four different slit sizes can be used in a slit holder assembly to give different spectral resolutions and spectral sampling values.

\begin{tabular}{lcc}
\hline Characteristic & UV & VIS \\
\hline Wavelength range & $290-400 \mathrm{~nm}$ & $415-695 \mathrm{~nm}$ \\
Spectral resolution in FWHMs & $0.34 ; 0.39 ; 0.43 ; 0.49 \mathrm{~nm}$ & $0.70 ; 0.75 ; 0.88 ; 1.00 \mathrm{~nm}$ \\
(slit size $=26.0 ; 32.5 ; 39.0 ; 45.5 \mu \mathrm{m})$ & & \\
Spectral sampling per FWHMs & $2.5 ; 2.8 ; 3.1 ; 3.5$ pixels & $2.5 ; 2.7 ; 3.1 ; 3.6$ pixels \\
Single pixel signal-to-noise ratio & $110(340 \mathrm{~nm})$ & $65(440 \mathrm{~nm})$ \\
Full cross-track field of view & \multicolumn{2}{c}{$45^{\circ}$} \\
Single pixel cross-track field of view & & $0.046^{\circ}$ \\
\hline
\end{tabular}

a $39 \mu \mathrm{m}$ slit.

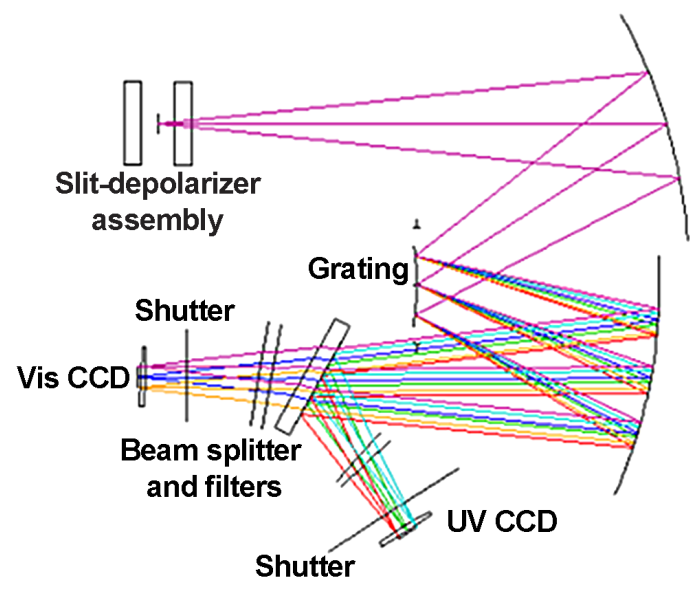

Figure 1. GeoTASO spectrometer design. First and second diffraction orders are separated into Vis and UV channels by the beam splitter and filters.

slit image is slightly smaller than the full array to allow for slight image shifting and to facilitate initial alignment, so that only the central 975 pixels in the cross-track dimension are well illuminated in nadir observations. In the wavelength dimension, the image covers 740 pixels on the UV detector and 1000 pixels on the visible detector. The spectral sampling is $0.14 \mathrm{~nm}$ for the UV and $0.28 \mathrm{~nm}$ for the visible detector.

The GeoTASO instrument design uses a reconfigurable slit and depolarization assembly for testing the sensitivity of trace gas retrievals to changing passband, spectral sampling and polarization. The $13 \mathrm{~mm}$ long slit can be replaced manually, in a precision-registered slit holder that maintains instrument alignment, by slits of various widths (26.0, 32.5, 39.0 and $45.5 \mu \mathrm{m})$. Under microscope testing, slit edges were free of pronounced jaggedness at high spectral frequencies, and were uniform in width to at least $\pm 2 \mu \mathrm{m}$, the limit of the microscope setup. A pair of electronically controlled photoelastic modulators (PEMs) positioned before and after the slit serve as a depolarizer (Illing, 2009) that can be turned off and on or adjusted to optimize depolarization at particular wavelengths during the flight. These are flat parallel windows

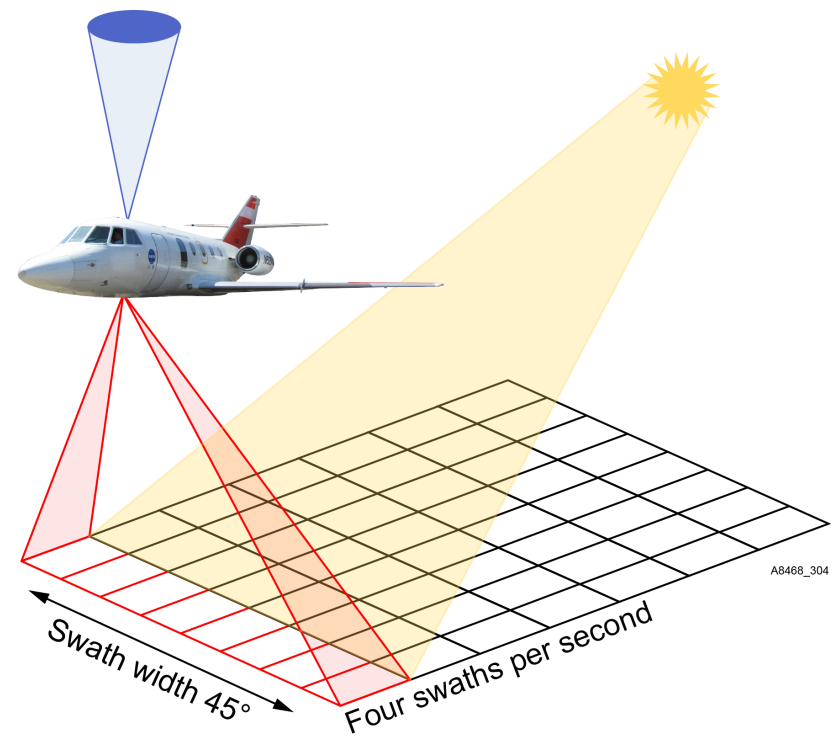

Figure 2. Schematic of GeoTASO measurement approach. The nadir observations are shown in red and zenith sky view in blue. In practice, there are approximately 975 spatial samples across the swath (after Heue et al., 2008).

tilted at a small oblique angle. There is a small lateral image shift due to the tilt, and a focus shift due to the optical path length, but no distortion.

The spectrometer and telescope are contained within thermally stabilized housing with continuous temperature monitoring. Each focal plane is chilled to $-25^{\circ} \mathrm{C}$, with an observed stability of $\pm 0.2^{\circ} \mathrm{C}$. The insulated enclosure around the optical bench is separately controlled to $24^{\circ} \mathrm{C}$ with a stability of $1-2^{\circ} \mathrm{C}$. The bench is graphite with a low coefficient of thermal expansion, and the flexure-attachment scheme is designed to athermalize optical positions over a wide range of temperatures. The instrument housing is mounted kinematically to the aircraft. On the NASA HU-25C Falcon aircraft, the housing is mounted to the seat rails and the telescope looks at the nadir direction through a fused silica window on the bottom of the aircraft. 


\subsection{Measurement strategy}

Figure 2 shows the geometry of the GeoTASO observations. At a typical flight altitude of $11 \mathrm{~km}$ above the surface, the $45^{\circ}$ FOV results in a cross-track FOV of $9.1 \mathrm{~km}$ for the full field. This results in a cross-track instantaneous FOV (IFOV) of approximately $9 \mathrm{~m}$ for each spatial sample. The $1.2 \mathrm{mrad}$ alongtrack IFOV (39 $\mu \mathrm{m}$ slit) projects to an along-track IFOV of $13-15 \mathrm{~m}$ at the ground. The along-track FOV is furthermore determined by the product of the detector integration time of $0.25 \mathrm{~s}$ and the aircraft ground speed, with some variation due to aircraft pitch. At typical aircraft ground speed $\left(\sim 200 \mathrm{~m} \mathrm{~s}^{-1}\right)$ and pitch, the along-track FOV is on the order of $50-80 \mathrm{~m}$.

Nadir measurements are typically interspersed with manually commanded zenith sky reference and dark current observations. GeoTASO collects zenith observations through an optical fiber bundle that looks out the top of the aircraft. As a result, the zenith spectra fill only the center of the FOV and are detected with sufficient signal for analysis over about 60 pixels in the cross-track dimension. A typical zenithsky measurement sequence collects about 580 such observations, resulting in approximately 35000 individual spectra per zenith sequence. Zenith sky spectra are co-added to improve the signal-to-noise ratio as described in Sect. 4.2. Dark current observations are also collected periodically by commanding the closure of shutters immediately in front of the CCD arrays.

\section{DISCOVER-AQ campaign}

DISCOVER-AQ was a NASA Earth Venture suborbital class mission which involved four field campaigns over 4 years, aimed at improving the ability of satellite observations to be applied for air quality monitoring (http://discover-aq.larc. nasa.gov/). As part of the campaigns, instruments on the NASA King Air B200 aircraft (remote sensing observations) and the P-3B aircraft (in situ observations) collected a large suite of trace gas, meteorological and aerosol observations in concert with stationary and mobile ground-based and shipbased remote sensing and in situ monitoring instruments. GeoTASO flew on the NASA HU-25C Falcon aircraft during the DISCOVER-AQ field campaigns in September 2013 (Texas) and July-August 2014 (Colorado).

\subsection{GeoTASO measurements during DISCOVER-AQ Texas 2013}

During the 2013 campaign, the GeoTASO instrument was based in southeast Houston at the William P. Hobby Airport and flew seven flights on 6 days between 12 and 24 September 2013, including inbound and outbound transits from and to the Falcon's base at NASA Langley Research Center in Virginia. Table 2 summarizes these flights, along with the slit size used for each flight. The inbound transit from Virginia included observations near Atlanta, Georgia, close to large power plants. The 16 September flight made a direct underpass of the Aura satellite as it passed over southern Oklahoma. This flight was made with the intention to compare with retrievals from the Ozone Monitoring Instrument (OMI) on Aura; although $\mathrm{OMI} \mathrm{NO}_{2}$ measurements on that day over Texas and Oklahoma were below the detection limit, GeoTASO was able to detect $\mathrm{NO}_{2}$ over Forth Worth, Texas. The 17 September observations were made primarily over water, in support of the ocean color segment of the GEO-CAPE mission, which aims to derive chlorophyll fluorescence and water-leaving radiances in the near-UV, visible and near-infrared from geostationary orbit. The 13, 14, 18 and 24 (Leg 1) September flights occurred over the greater Houston area and enabled observations of pollution from industrial and urban transportation sources. Leg 2 of the 24 September flights passed over three large power plants in North Carolina during the aircraft's transit back to Virginia. In this paper, we examine data from the Houston urban flights on $13,14,18$ and 24 September.

\subsection{Additional data sources}

In this study, we use $\mathrm{NO}_{2}$ data from ground, aircraft and satellite-based measurements, as well as model data produced for the campaign. The surface observations are primarily from 12 DISCOVER-AQ campaign sites in the Houston area, which are listed in Table 3 along with the instruments deployed at the sites. Figure 3 shows the location of these DISCOVER-AQ sites.

\subsubsection{Pandora}

Total column $\mathrm{NO}_{2}$ was measured by Pandora spectrometers (Herman et al., 2009) during DISCOVER-AQ Texas by direct sun observation with a temporal resolution of $90 \mathrm{~s}$, a typical precision of $2.7 \times 10^{14}$ molecules $\mathrm{cm}^{-2}$ and an accuracy of $2.7 \times 10^{15}$ molecules $\mathrm{cm}^{-2}$. Pandora $\mathrm{NO}_{2}$ is determined from the difference between the direct sun observation and a reference spectrum derived using clean observations on a clear day. Total column $\mathrm{NO}_{2}$ is derived using $\mathrm{NO}_{2}$ cross sections from Vandaele et al. (1998) at an effective temperature of $250 \mathrm{~K}$ derived from $\mathrm{NO}_{2}$ and temperature profiles as described in Herman et al. (2009). We use column $\mathrm{NO}_{2}$ data from 15 Pandora instruments deployed at 11 sites coincident with GeoTASO overpasses.

\subsubsection{TCEQ SLAMS}

The Environmental Protection Agency (EPA) coordinates a series of sites as part of the national State and Local Air Monitoring Stations (SLAMS) and relevant air quality networks which monitor ambient air quality in the United States at rural, suburban and urban locations. In Texas, these are operated by the Texas Commission on Environmental Quality (TCEQ). We use TCEQ SLAMS $\mathrm{NO}_{2}$ measurements mea- 
Table 2. Summary of GeoTASO flights during Discover-AQ Texas 2013. LT $=\mathrm{UTC}-4 \mathrm{~h}$ for 12 September and LT $=\mathrm{UTC}-5 \mathrm{~h}$ for other days.

\begin{tabular}{llrr}
\hline Date & Flight summary & Flight time $(\mathrm{LT})$ & Slit size $(\mu \mathrm{m})$ \\
\hline 12 September & Flight to Houston from Virginia & $14: 37-17: 50$ & 39.0 \\
13 September & Houston & $08: 20-11: 34$ & 39.0 \\
14 September & Houston & $13: 48-17: 06$ & 32.5 \\
16 September & OMI satellite underpass, Oklahoma & $13: 15-15: 46$ & 39.0 \\
17 September & Boat and water overpasses & $08: 35-10: 27$ & 45.5 \\
18 September & Houston & $09: 01-12: 06$ & 26.0 \\
24 September & Leg 1: Houston & $10: 07-12: 08$ & 45.5 \\
& Leg 2: Flight to Virginia, power plant overpasses & $14: 10-16: 16$ & 45.5 \\
\hline
\end{tabular}

Table 3. DISCOVER-AQ sites used in GeoTASO validation and site instrumentation. The Pandora ID is an identification number given to each individual Pandora instrument.

\begin{tabular}{lrrll}
\hline Site & Latitude $\left(^{\circ}\right)$ & Longitude $\left(^{\circ}\right)$ & Pandora ID & In situ instrument \\
\hline Channelview & 29.803 & -95.126 & P26 & TCEQ FRM \\
Conroe & 30.350 & -95.425 & P31 & TCEQ FRM \\
Deer Park & 29.670 & -95.128 & P32 & TCEQ FRM \\
Galveston & 29.254 & -94.861 & P34 & photolytic, TCEQ FRM \\
Harris & 30.039 & -95.674 & P30 & TCEQ FRM \\
La Porte & 29.672 & -95.065 & P38, P39 & CAPS, EPA FRM \\
Manvel Croix & 29.520 & -95.392 & P33 & CRD, TCEQ FRM \\
Moody Tower & 29.718 & -95.341 & P28, P35 & photolytic \\
Seabrook Park & 29.901 & -95.326 & P27 & photolytic, TCEQ FRM \\
Smith Point & 29.546 & -94.787 & P8, P29, P36 & CAPS \\
Texas Avenue & 29.753 & -95.350 & & photolytic, TCEQ FRM \\
West Houston & 29.833 & -95.657 & P18 & \\
\hline
\end{tabular}

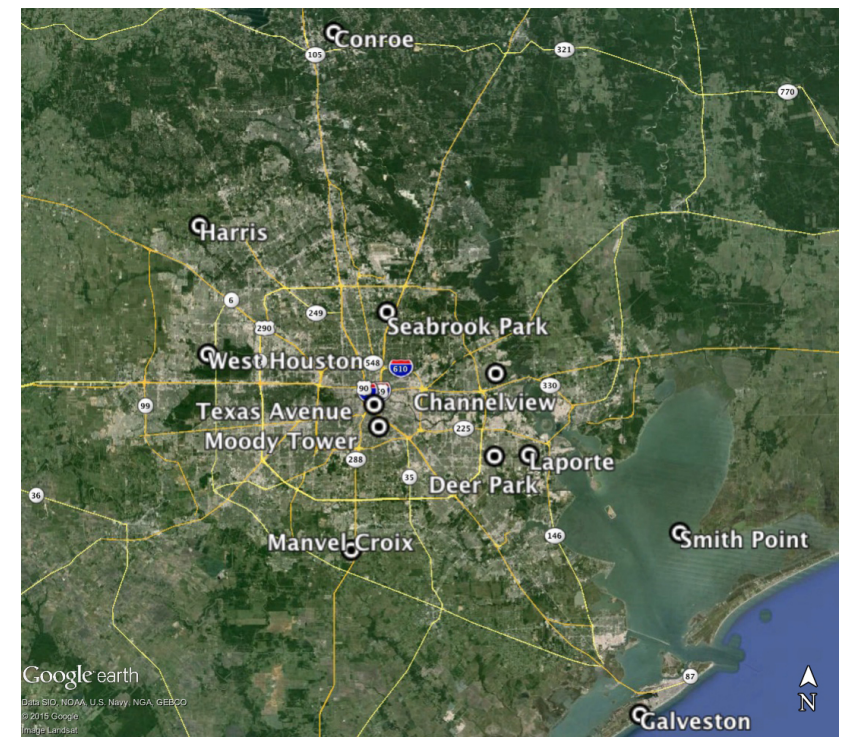

Figure 3. Location of ground sites in Houston area during DISCOVER-AQ 2013. Major roads are shown in yellow. sured by chemiluminescence and reported hourly at 11 sites in the Houston area coincident with GeoTASO overpasses during DISCOVER-AQ Texas. These include monitors colocated with eight DISCOVER-AQ science sites listed in Table 3. These measurements are made by Federal Reference Method (FRM) chemiluminescence using molybdenum converters and are known to have high measurement biases under certain conditions relative to other observations (Lamsal et al., 2008). The FRM instruments' listed detection limit is $2.7 \mathrm{ppbv}$.

\subsubsection{EPA research instrumentation}

The EPA deployed five research instruments measuring $\mathrm{NO}_{2}$ every $60 \mathrm{~s}$ or less at four sites. These included two Cavity Attenuated Phase Shift (CAPS) instruments which measure $\mathrm{NO}_{2}$ directly by absorption at $450 \mathrm{~nm}$ with an uncertainty of $\pm 10 \%$, two chemiluminescence $\mathrm{NO}_{x}$ analyzers with photolytic converters with an $\mathrm{NO}_{2}$ uncertainty of $\pm 15 \%$ and a high-sensitivity FRM chemiluminescence molybdenum converter instrument deployed in tandem with a CAPS instrument. 


\subsubsection{NOAA instrumentation}

A cavity ring-down (CRD) instrument was deployed by the National Oceanic and Atmospheric Administration (NOAA) and University of Maryland at the Manvel Croix science site in the south of Houston. The CRD instrument measured ambient $\mathrm{NO}_{2}$ every $10 \mathrm{~s}$ with an uncertainty of $\pm 5 \%$. The instrument was calibrated with a NIST-traceable $\mathrm{NO}_{2}$ standard as well as the gas-phase titration method (Brent et al., 2013). A NOAA chemiluminescence photolytic converter monitor was also deployed at the Galveston site and reported measurements every $60 \mathrm{~s}$, with an uncertainty of $\pm 10 \%$.

\subsubsection{University of Houston instrumentation}

The University of Houston made measurements of $\mathrm{NO}_{2}$ at altitudes of 7 and $70 \mathrm{~m}$ at the Moody Tower site in downtown Houston. These were collected with a chemiluminescence monitor fitted with a photolytic converter and have a reported uncertainty of $\pm 12 \%$. Data are reported every $5 \mathrm{~min}$.

\subsubsection{GCAS}

The GCAS instrument (Kowalewski and Janz, 2014) was deployed on the NASA King Air B200 aircraft as part of the campaign's airborne remote sensing payload, which also included the NASA High Spectral Resolution Lidar (HSRL) instrument (Hair et al., 2008) for aerosol studies. GCAS operates in a similar fashion to GeoTASO, using a 2-D CCD array detector to map slant columns of $\mathrm{NO}_{2}$ in two dimensions. The instrument uses an Offner imaging spectrometer with two $1072 \times 1024$ (spectral $\times$ spatial) pixel detector arrays in the UV/visible (300-490 $\mathrm{nm}$ ) and visible/near-infrared (480$900 \mathrm{~nm}$ ). The UV/visible channel used for $\mathrm{NO}_{2}$ retrievals has a spectral sampling of $0.2 \mathrm{~nm}$ and a spectral resolution of $0.57 \mathrm{~nm}$. The full cross-track FOV covers $45^{\circ}$. At wavelength $440 \mathrm{~nm}$ and at a spatial resolution of $250 \mathrm{~m} \times 500 \mathrm{~m}$, the signal-to-noise ratio is on the order of 540. GCAS is a successor to the Airborne Compact Atmospheric Mapper (ACAM) scanning instrument (Liu et al., 2015) and flew in its first campaign deployment during DISCOVER-AQ Texas.

\subsubsection{GOME-2}

The Global Ozone Monitoring Experiment-2 (GOME-2) instruments (Munro et al., 2016) were launched on the EUMETSAT satellites Metop-A in 2006 and Metop-B in 2013. GOME-2 instruments make nadir observations of backscattered solar radiation from 240 to $790 \mathrm{~nm}$. Only Metop-A data are considered here, as there were no cloud-free coincidences with Metop-B during DISCOVER-AQ Texas. As of mid-2013, the GOME-2/Metop-A nominal pixel resolution is $40 \times 40 \mathrm{~km}^{2}$. We use the publicly available BIRAIASB/KNMI GOME-2 $\mathrm{NO}_{2}$ product TM4NO2A version 2.3 (http://www.temis.nl) (Boersma et al., 2004).

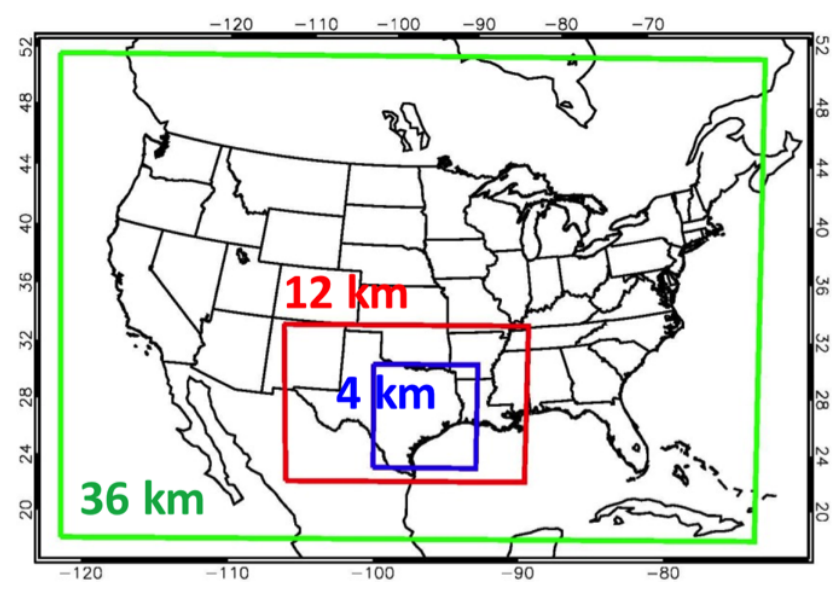

Figure 4. 36, 12 and $4 \mathrm{~km}$ CMAQ modeling domains.

\subsubsection{CMAQ model}

The EPA's Community Multiscale Air Quality (CMAQ) version 5.0.2 modeling system (Byun and Schere, 2006) was used to simulate air quality from 18 August 2013 through 1 October 2013. CMAQ used offline meteorology from the Advanced Research Weather Research and Forecasting (WRFARW) model (Skamarock et al., 2008) via the MeteorologyChemistry Interface Processor (MCIP) (Otte and Pleim, 2010). This time period covers the entire DISCOVER-AQ Texas field deployment in September 2013 plus additional days in August to provide adequate model spin-up time. The CMAQ model simulations used in the GeoTASO analysis have a spatial resolution of $4 \times 4 \mathrm{~km}^{2}$ and a temporal resolution of $20 \mathrm{~min}$. The local bay and sea breezes that affect air quality in this region are best simulated at the high resolutions of a regional model over those available from most global models. We apply CMAQ and WRF due to previous success capturing local-scale bay and sea breezes with these models (Loughner et al., 2011).

Figure 4 shows the 36,12 and $4 \mathrm{~km}$ modeling domains. The $12 \mathrm{~km}$ North American Mesoscale (NAM) model was used for meteorological initial and boundary conditions. Observational and analysis nudging were performed on all domains. Observational nudging was done using the $\mathrm{Na}$ tional Centers for Environmental Prediction (NCEP) Automated Data Processing (ADP) Global Surface (http://rda. ucar.edu/datasets/ds461.0/) and Upper Air (http://rda.ucar. edu/datasets/ds351.0/) Observational Weather Data.

WRF was run using an iterative technique developed at the EPA (Appel et al., 2014). The initial WRF run performed analysis nudging on all domains based on the $12 \mathrm{~km}$ NAM. The second WRF run performed analysis nudging on all domains based on the $12 \mathrm{~km}$ NAM except for $2 \mathrm{~m}$ temperature and humidity for the $4 \mathrm{~km}$ domain, for which $2 \mathrm{~m}$ temperature and humidity from the $4 \mathrm{~km}$ initial WRF simulation were used for nudging. This modeling technique prevented 
Table 4. WRF and CMAQ model options.

\begin{tabular}{ll}
\hline Weather Research and Forecasting (WRF) Version 3.6.1 model options \\
\hline Radiation & Longwave: RRTM; Shortwave: Goddard \\
Surface layer & Pleim-Xiu \\
Land surface model & Pleim-Xiu \\
Boundary layer & ACM2 \\
Cumulus & Kain-Fritsch \\
Microphysics & WSM-6 \\
Nudging & Observational and analysis nudging \\
Damping & Vertical velocity and gravity waves damped at top of modeling domain \\
Sea surface temperatures (SSTs) & Multi-scale Ultra-high Resolution (MUR) SST analysis (1 km resolution) \\
\hline CMAQ version 5.0.2 model options & \\
\hline Chemical mechanism & CB05 \\
Aerosols & AE5 \\
Dry deposition & M3DRY \\
Vertical diffusion & ACM2 \\
Emissions & 2012 TCEQ anthropogenic emissions \\
& Biogenic (BEIS) and lightning emissions calculated within CMAQ \\
Initial and boundary conditions & MOZART CTM \\
\hline
\end{tabular}

the relatively coarse NAM $12 \mathrm{~km}$ model from degrading the high-resolution $4 \mathrm{~km}$ domain. The second iterative WRF runs were used to drive the CMAQ simulation. The CMAQ simulation employs 45 vertical levels, extending from the surface to $50 \mathrm{hPa}$. Table 4 summarizes WRF and CMAQ options.

\section{Analysis method}

The calculation of $\mathrm{NO}_{2}$ vertical columns is performed using a two-step approach. First, we retrieve the slant column amount of the gas in the viewing path from each nadir spectrum by direct fitting (Chance, 1998) with a zenith sky spectrum as a reference. We then convert the slant column to a vertical column of $\mathrm{NO}_{2}$ using an air mass factor (AMF) that considers viewing geometry and radiative transfer. Preprocessing of the data involves calibration of raw Level 0 spectra to calibrated Level 1B spectra, and calculation of zenith sky reference spectra.

The GeoTASO retrieval algorithm is based on existing algorithms developed at the Smithsonian Astrophysical Observatory for GOME, GOME-2, OMI and OMPS (Ozone Mapping and Profiler Suite) trace gas products (e.g., Chance, 1998; Chance et al., 2000; Nowlan et al., 2011; Chan Miller et al., 2014; González Abad et al., 2015a, b), which are also the heritage algorithms for TEMPO trace gas retrievals.

\subsection{Calibration}

We convert spectra from detector counts to radiometrically calibrated spectra using laboratory measurements of sensor wavelength scale and responsivity over the full FOV. Calibrations use an integrating sphere with line or broad spectrum sources. The integrating sphere is referenced to known cali- bration sources to give an absolute radiance calibration with approximately $10 \%$ uncertainty in the visible. The calibration uses measurements from pixels outside the imaging area to remove smear signal and apply a stray light correction. The mean out-of-band signal in the visible channel was less than $1 \%$ of the mean in-band illumination, as measured using an incandescent source and a $445 \mathrm{~nm}$ longpass filter. Polarization sensitivity was measured but not included in these preliminary radiance calibrations as it is at a low level $(<5 \%)$.

The instrument slit functions measured in the laboratory for the four instrument slits indicate that their shapes and widths are consistent across both the FOV and wavelength dimensions of the detector arrays (Leitch et al., 2014). We confirm the stability of the slit shape with cross-track position and wavelength using flight data by fitting a slit function to nadir spectra as a preliminary step in the trace gas retrievals.

This approach follows a wavelength-dependent slit and wavelength calibration method previously implemented in the retrieval algorithm to determine slit shape and wavelength calibration from GOME (Liu et al., 2005) and GOME2 (Cai et al., 2012) irradiance spectra using a high-resolution solar reference (Chance and Kurucz, 2010), but simultaneously retrieves preliminary trace gas columns and Ring scaling parameters to remove the effects of atmospheric absorption and the Ring effect present in nadir spectra (Liu et al., 2015). We find the slit function is best modeled for the two largest slit sizes in the visible (Table 1) using a hybrid Gaussian and flat-top Gaussian defined by

$$
F=(1-w) \exp \left[\frac{-\Delta \lambda^{2}}{(h(1 \pm a))^{2}}\right]+w \exp \left[\frac{-\Delta \lambda^{4}}{\left(h^{\prime}\left(1 \pm a^{\prime}\right)\right)^{4}}\right]
$$




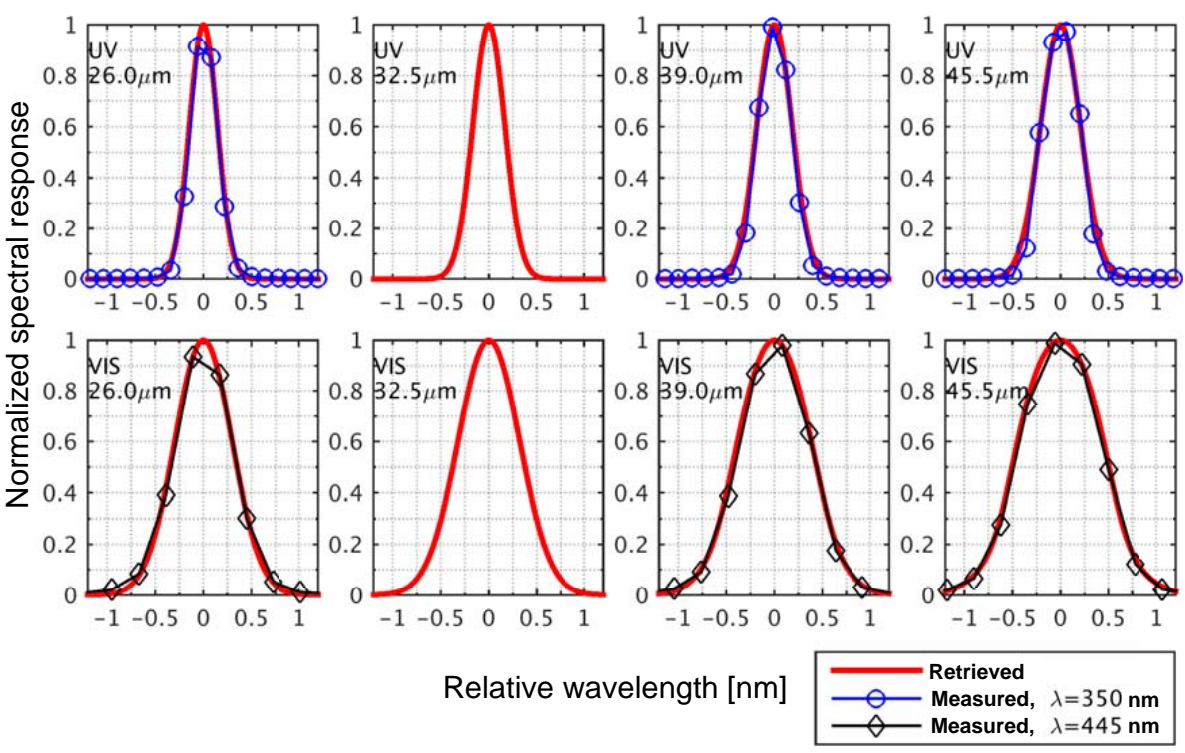

Figure 5. Slit function shapes retrieved from nadir radiance data for UV and VIS spectrometers and those recorded post-flight in the laboratory at 350 and $445 \mathrm{~nm}$ for the center FOV position. Data were not collected in the laboratory for the $32.5 \mu \mathrm{m}$ slit due to time constraints. Data for the $39 \mu \mathrm{m}$ slit are shown at $440 \mathrm{~nm}$, as $445 \mathrm{~nm}$ was not recorded.

where the algorithm simultaneously fits a relative weighting $w$ between the standard and flat-top Gaussian, and terms $h$ (standard) and $h^{\prime}$ (flat-top), which represent the half-width at $1 / \mathrm{e}$, and $a$ and $a^{\prime}$, which represent asymmetry in the Gaussians. Table 5 lists the retrieved parameters for each slit, and the resulting full-width at half maximums (FWHMs) are additionally included in Table 1. Although only visible trace gas retrievals are performed in this paper, we include the UV calibration for completeness. For the UV and two smallest slits in the visible, the slit shape is closest approximated by a Gaussian with no flat-top component. These slit shapes are only minimally asymmetric.

Figure 5 shows the slit functions determined using flight data with those measured in the laboratory for the center FOV position. Laboratory measurements were performed for the 26, 39 and $45.5 \mu \mathrm{m}$ slit sizes at three field angles and several wavelengths across the array after the campaign. Our retrieved slit shapes are in good agreement with the measured slit functions, indicating that the slit function parameterization and retrieval using nadir data are both valid for the trace gas retrievals. In the array's spectral dimension, the FWHM changes by less than $0.015 \mathrm{~nm}$ across the entire detector array, with the FWHM slightly higher at the center of the array than at the edges. In the cross-track spatial dimension, the visible FWHM varies by less than $0.01 \mathrm{~nm}$, with the FWHM varying from narrowest at the leftmost crosstrack positions to widest at the rightmost positions. The UV FWHM is narrowest at the center cross-track positions, and increases by $0.01 \mathrm{~nm}$ by the detector edges. These calibrations do not show any significant change in the slit shape as
Table 5. Retrieved slit parameters for slit function described by Eq. (1) and resulting full-width at half-maximums (FWHMs).

\begin{tabular}{|c|c|c|c|c|}
\hline & \multicolumn{4}{|c|}{ Slit size } \\
\hline & $26.0 \mu \mathrm{m}$ & $32.5 \mu \mathrm{m}$ & $39.0 \mu \mathrm{m}$ & $45.5 \mu \mathrm{m}$ \\
\hline \multicolumn{5}{|l|}{ UV } \\
\hline$h$ & 0.217 & 0.239 & 0.263 & 0.292 \\
\hline$a$ & -0.048 & -0.013 & -0.013 & -0.0045 \\
\hline$h^{\prime}$ & 0 & 0 & 0 & 0 \\
\hline$a^{\prime}$ & 0 & 0 & 0 & 0 \\
\hline$w$ & 0 & 0 & 0 & 0 \\
\hline FWHMs & $0.34 \mathrm{~nm}$ & $0.39 \mathrm{~nm}$ & $0.43 \mathrm{~nm}$ & $0.49 \mathrm{~nm}$ \\
\hline \multicolumn{5}{|l|}{ VIS } \\
\hline$h$ & 0.440 & 0.475 & 0.542 & 0.627 \\
\hline$a$ & -0.048 & -0.035 & -0.034 & -0.032 \\
\hline$h^{\prime}$ & 0 & 0 & 0.470 & 0.627 \\
\hline$a^{\prime}$ & 0 & 0 & 0.074 & 0.073 \\
\hline$w$ & 0 & 0 & 0.133 & 0.283 \\
\hline FWHMs & $0.70 \mathrm{~nm}$ & $0.75 \mathrm{~nm}$ & $0.88 \mathrm{~nm}$ & $1.00 \mathrm{~nm}$ \\
\hline
\end{tabular}

described in Eq. (1) in either the spectral or spatial dimension.

The approach simultaneously determines a wavelength-topixel registration represented by a second-order polynomial by fitting the spectrum to a high-resolution solar reference (Chance and Kurucz, 2010). 


\subsection{Zenith sky reference spectra}

We determine a mean zenith sky reference spectrum for each nadir observation using the nearest three zenith sky sequences closest in time, which usually occur within $20 \mathrm{~min}$ of the nadir observation. The signal-to-noise ratio of the resulting zenith spectrum varies with solar zenith angle and wavelength, but is approximately 1000-2000 in the $\mathrm{NO}_{2}$ fitting window. In future, averaging could include even more spectra to reduce the influence of zenith noise in the retrievals.

\subsection{Spectral fitting}

We determine $\mathrm{NO}_{2}$ slant columns from individual spectra at native spatial resolution between wavelengths 420 and $465 \mathrm{~nm}$ by simultaneously fitting line-of-sight $\mathrm{NO}_{2}$ slant columns and other parameters listed in Table 6.

The fit includes molecular absorbers $\mathrm{NO}_{2}, \mathrm{O}_{3}, \mathrm{H}_{2} \mathrm{O}$ vapor and $\mathrm{O}_{2}-\mathrm{O}_{2}$, as well as the following pseudo-absorbers: a Ring spectrum that accounts for filling-in of Fraunhofer lines in the solar spectrum due to rotational Raman scattering; undersampling of the spectrum that occurs when spectral sampling is less than $\sim 3$ pixels across the FWHM (Chance et al., 2005), which is necessary for the 26 and $32.5 \mu \mathrm{m}$ slit sizes where sampling is 2.5 and 2.7 pixels/FWHM, respectively; and baseline (fourth order) and scaling (fifth order) polynomials to represent low frequency features in the spectrum due to aerosols, molecular scattering, wavelength-dependent albedo and low-order effects that may not be accounted for properly in radiometric calibration. A wavelength shift is also fit to account for the relative difference in wavelengthdetector pixel registration between the nadir radiance and reference spectra.

In this study, we co-add fitted $\mathrm{NO}_{2}$ slant columns at native spatial resolution using 27 across-track and four along-track pixels to reduce noise in the columns, resulting in an effective spatial footprint at the surface of about $250 \mathrm{~m} \times 250 \mathrm{~m}$. For our analysis of high- $\mathrm{NO}_{2}$ regions where $\mathrm{NO}_{2}$ signal dominates over noise, we present data at this spatial resolution as an optimization of spatial resolution and precision. In the visible spectrometer, we find that fitting uncertainties derived from slant columns co-added post-retrieval to this resolution are typically within a few percent of those derived using spectra co-added pre-retrieval with a common mode fit in the retrieval (e.g., Martin et al., 2002; Chan Miller et al., 2014; González Abad et al., 2015a), indicating that influences from systematic issues are low in the $250 \mathrm{~m} \times 250 \mathrm{~m}$ visible results. Figure 7 shows spectral fits of $\mathrm{NO}_{2}$ optical depth at different spatial resolutions.

While satellite observations cover large ground footprints (on the order of tens of kilometers), which require the derivation of cloud fractions to ensure large amounts of data are not discarded, the high native spatial resolution of GeoTASO pixels allows the total removal of cloudy observations and only cloud-free data are presented here. Cloudy pixels are removed using a straightforward limit on the mean radiance by filtering for all single frames where the mean radiance in the $\mathrm{NO}_{2}$ fitting window exceeds $2 \times$ $10^{13}$ photons $\mathrm{cm}^{-2} \mathrm{~nm}^{-1} \mathrm{~s}^{-1} \mathrm{sr}^{-1}$.

Mean root-mean-square (rms) fitting uncertainties in normalized spectra at native resolution are on the order of 0.01 for bright, cloud-free scenes, and 0.02 for dimmer scenes. For retrievals using co-added spectra, the mean $\mathrm{rms}$ is $\sim$ $1.6 \times 10^{-3}$ at $250 \mathrm{~m} \times 250 \mathrm{~m}$ resolution. GeoTASO design requirements were driven by $\mathrm{NO}_{2}$ fitting at a resolution of $1 \mathrm{~km} \times 1 \mathrm{~km}$. At this resolution, the mean rms is $\sim 7 \times 10^{-4}$, which is comparable to previous fitting results in this spectral region (Martin et al., 2002; Chan Miller et al., 2014), and includes some remaining systematic residuals as well as other residuals which are not necessarily systematic from co-adding inhomogeneous scenes and different wavelength positions and slit functions. The 39 and $45.5 \mu \mathrm{m}$ slit sizes give the best fitting performance, while rms fitting errors are larger by $15 \%$ for the $32.5 \mu \mathrm{m}$ slit and by $30 \%$ for the $26.0 \mu \mathrm{m}$ slit. The exact source of these rms differences still needs investigation, but they are likely due to differences in throughput and in part to an imperfect undersampling correction.

\subsection{Cross-track striping}

GeoTASO $\mathrm{NO}_{2}$ slant column retrievals show the artificial cross-track striping that is common in many 2-D push broom sensors (Boersma et al., 2011; Popp et al., 2012). The magnitude of this striping is persistent throughout each flight, with little day-to-day variation except between campaigns when instrument modifications have likely affected radiometric calibration.

To calculate a destriping correction, we determine the daily offset from the estimated $\mathrm{NO}_{2}$ slant columns from the CMAQ model as a function of cross-track position, using a large number of retrievals over the relatively clean Gulf of Mexico. The details of this calculation using model calculations and air mass factors are described in the next section.

Figure $6 a$ shows the offset determined from 1 million spectra on 13 September 2013. At native resolution, striping for the Texas campaign can reach a magnitude of $\pm 4 \times$ $10^{16}$ molecules $\mathrm{cm}^{-2}$ but is typically on the order of $\pm 9 \times$ $10^{15}$ molecules $\mathrm{cm}^{-2}$. Figures $6 \mathrm{~b}$ and $\mathrm{c}$ show the effects of the striping and corrected columns at $250 \mathrm{~m} \times 250 \mathrm{~m}$ resolution for a clear region over water. At co-added resolution, the striping is reduced in magnitude, with individual stripes occasionally as large as $\pm 5 \times 10^{15}$ molecules $\mathrm{cm}^{-2}$. The application of the striping correction removes any evidence of cross-track striping along the entire flight.

\subsection{Air mass factor calculation}

The conversion of retrieved slant column $S$ to vertical column $V$ requires an air mass factor (AMF) $A$ that describes 
Table 6. Reference cross sections and parameters fit in $\mathrm{NO}_{2}$ retrieval.

\begin{tabular}{ll}
\hline Parameter & Note \\
\hline $\mathrm{NO}_{2}$ & Vandaele et al. (1998), 294 K \\
$\mathrm{O}_{3}$ & Brion et al. (1993), 218 and 295 K \\
$\mathrm{H}_{2} \mathrm{O}$ vapor & Rothman et al. (2013), 288 K, 1 atm \\
$\mathrm{O}_{2}-\mathrm{O}_{2}$ & Thalman and Volkamer (2013), 293 K \\
Ring spectrum & Chance and Spurr (1997) \\
Undersampling & Chance et al. (2005) \\
Baseline polynomial & fourth order \\
Scaling polynomial & fifth order \\
Wavelength shift & \\
\hline
\end{tabular}
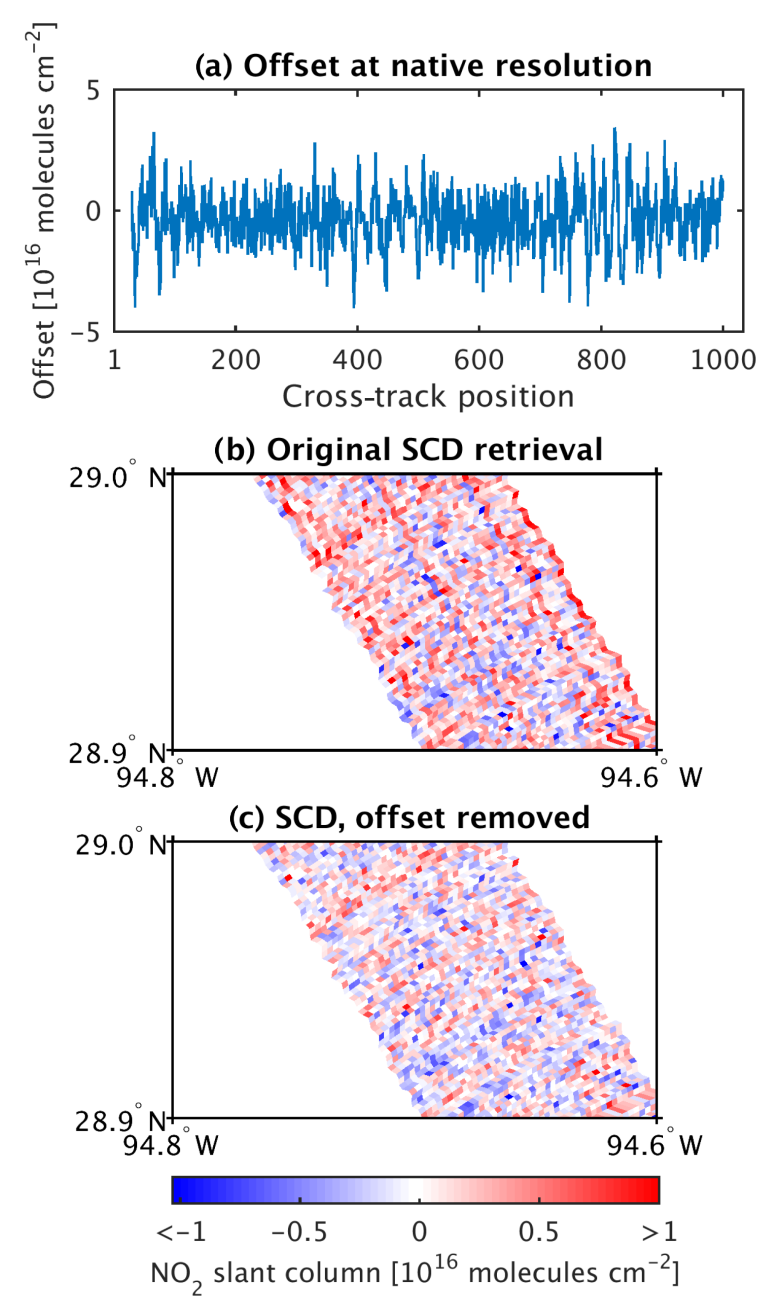

Figure 6. (a) Mean $\mathrm{NO}_{2}$ slant column density (SCD) as a function of cross-track position for retrievals at native spatial resolution derived from 1 million spectra on 13 September 2014 over a relatively clean area in the Gulf of Mexico; (b) original co-added slant column retrieval at $250 \mathrm{~m} \times 250 \mathrm{~m}$ without cross-track striping correction; and (c) co-added slant column density at $250 \mathrm{~m} \times 250 \mathrm{~m}$ corrected for cross-track striping. the vertically resolved contribution of the trace gas, where

$$
V=\frac{S}{A} \text {. }
$$

The magnitude of the AMF depends on the vertical profile of the gas of interest $\left(\mathrm{NO}_{2}\right)$, ozone profile, aerosol optical depth, molecular scattering, surface albedo, cloud top pressure and radiative cloud fraction. In the case of the GeoTASO data, the high spatial resolution of native pixel observations allows clouds to be removed from processed data, and all coadded pixels are assumed to be clear-sky. We calculate AMFs for each local co-added scene following the formulation of Palmer et al. (2001), with scattering weights calculated using the radiative transfer model VLIDORT (Spurr, 2006).

The scattering weights $w(z)$ describe the sensitivity of the measurement to different altitude layers, and can be used with any trace gas profiles in model and instrument comparisons. They are related to the AMF by

$A=\int_{z} w(z) s(z) \mathrm{d} z$,

with the shape factor $s(z)$ describing the normalized density $x(z)$ of the trace gas of interest at altitude $z$ :

$s(z)=\frac{x(z)}{\int_{z} x(z) \mathrm{d} z}$.

The surface reflectivity representation in the scattering weight calculation uses bidirectional reflectance distribution functions (BRDFs) (Schaaf et al., 2002) determined from the high-resolution ( 30 arc second) MODIS BRDF MCD43GF V005 Band 3 product centered at $470 \mathrm{~nm}$ (http://www.umb.edu/spectralmass/terra_aqua_modis/ modis_brdf_albedo_product_mcd43). We determine the scattering weights and AMF at $470 \mathrm{~nm}$, which is the closest wavelength where MODIS BRDFs are available. Where MODIS BRDF values are not available over water, the surface is represented as Lambertian, with an albedo of 0.03 .

Tropospheric trace gas profiles are from the CMAQ model at $4 \mathrm{~km} \times 4 \mathrm{~km}$ resolution. Stratospheric $\mathrm{NO}_{2}$ profiles are 
from a climatology from the PRATMO chemical box model (Prather, 1992; McLinden et al., 2000). A monthly ozone climatology determined from the OMI ozone profile product (Liu et al., 2010) is used in the stratosphere.

We determine the vertical column from the retrieved differential slant column $\mathrm{d} S$, which represents the difference between the nadir slant column $S$ and the reference slant column $S_{\mathrm{R}}$ taken from zenith observations during these flights. In addition, we consider an offset expressed as a slant column $S_{\mathrm{O}}$ to remove striping in the retrieved $\mathrm{NO}_{2}$ as detailed in Sect. 4.4. The differential slant column is then represented as a function of the slant column below $\left(S^{\downarrow}\right)$ and above $\left(S^{\uparrow}\right)$ the aircraft by

$\mathrm{d} S=\left(S^{\downarrow}+S^{\uparrow}\right)-\left(S_{\mathrm{R}}^{\downarrow}+S_{\mathrm{R}}^{\uparrow}\right)+S_{\mathrm{O}}$,

with the offset $S_{\mathrm{O}}$ determined from a retrieved differential slant column $\mathrm{d} S_{\mathrm{O}}$ retrieved over a relatively clean area of the flight and defined as

$\mathrm{d} S_{\mathrm{O}}=\left(S_{\mathrm{O}}^{\downarrow}+S_{\mathrm{O}}^{\uparrow}\right)-\left(S_{\mathrm{R}, \mathrm{O}}^{\downarrow}+S_{\mathrm{R}, \mathrm{O}}^{\uparrow}\right)+S_{\mathrm{O}}$.

By substituting the product of the vertical column and air mass factor for the slant column, we can solve for the vertical column below the aircraft:

$V^{\downarrow}=\frac{\mathrm{d} S-V^{\uparrow} A^{\uparrow}+V_{\mathrm{R}}^{\downarrow} A_{\mathrm{R}}^{\downarrow}+V_{\mathrm{R}}^{\uparrow} A_{\mathrm{R}}^{\uparrow}-S_{\mathrm{O}}}{A^{\downarrow}}$,

where

$S_{\mathrm{O}}=\mathrm{d} S_{\mathrm{O}}-V_{\mathrm{O}}^{\downarrow} A_{\mathrm{O}}^{\downarrow}-V_{\mathrm{O}}^{\uparrow} A_{\mathrm{O}}^{\uparrow}+V_{\mathrm{R}, \mathrm{O}}^{\downarrow} A_{\mathrm{R}, \mathrm{O}}^{\downarrow}+V_{\mathrm{R}, \mathrm{O}}^{\uparrow} A_{\mathrm{R}, \mathrm{O}}^{\uparrow} \cdot$

The air mass factor below the aircraft $A^{\downarrow}$ is determined using the integration from the surface altitude $z_{0}$ to the aircraft altitude $z_{\mathrm{ac}}$, with

$$
A^{\downarrow}=\int_{z_{0}}^{z_{\mathrm{ac}}} w(z) s(z) \mathrm{d} z
$$

while the air mass factor above the aircraft $A^{\uparrow}$ is determined using the integration from the aircraft altitude to the top of the atmosphere at $z_{\mathrm{TOA}}$, with

$$
A^{\uparrow}=\int_{z_{\mathrm{ac}}}^{z_{\mathrm{TOA}}} w(z) s(z) \mathrm{d} z .
$$

For a typical case where measurements are made from a flight altitude of $11 \mathrm{~km}, V^{\downarrow}$ and $V^{\uparrow}$ are approximately equivalent to the tropospheric and stratospheric components of the $\mathrm{NO}_{2}$ column, respectively. In these equations, $\mathrm{d} S$ and $\mathrm{d} S_{\mathrm{O}}$ are determined from the measurements, while the vertical columns and air mass factors are determined using the modeled atmosphere. In practice, as long as the zenith reference

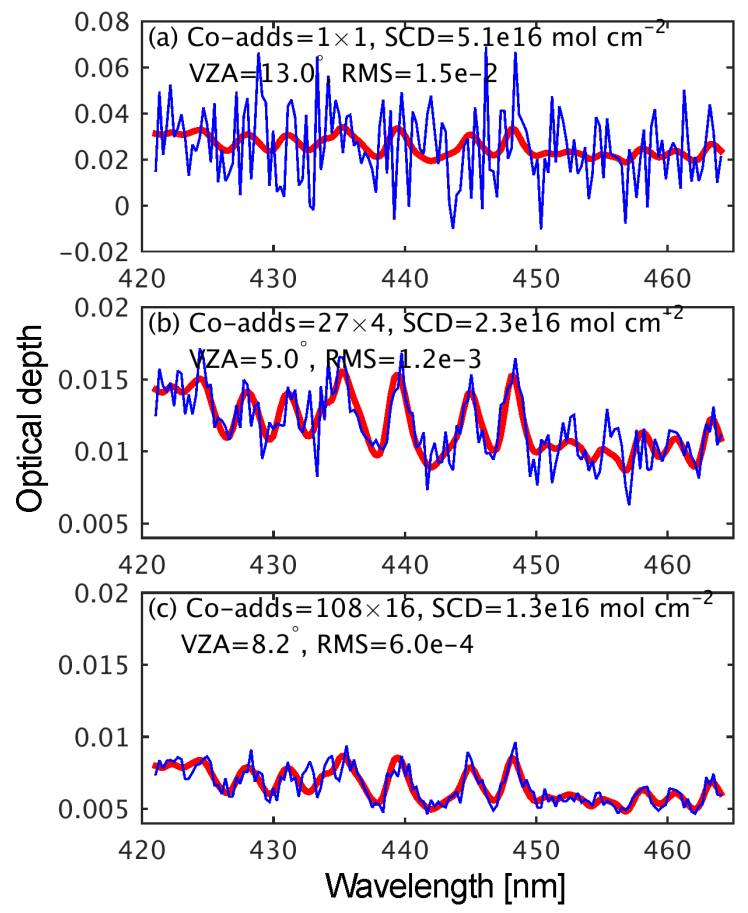

Figure 7. Sample $\mathrm{NO}_{2}$ spectral fits showing observed (blue) and simulated (red) optical depths from spectra collected over the south of Houston $\left(29.70^{\circ} \mathrm{N}, 95.24^{\circ} \mathrm{W}\right)$ on 13 September 2013 at 10:46 LT, with a solar zenith angle (SZA) of $44.1^{\circ}$, for (a) native resolution (no co-adding); (b) $250 \mathrm{~m} \times 250 \mathrm{~m}$ resolution $(27 \times 4$ coadds); and (c) $1 \mathrm{~km} \times 1 \mathrm{~km}$ resolution $(108 \times 16$ co-adds $)$.

is collected close in time and location to the nadir observation, the terms representing the reference and nadir columns are similar, although they do not cancel entirely. The effect of the column below the aircraft on the zenith observation also tends to be small. Although these terms are considered in these GeoTASO AMF calculations, the observed differential slant column and the tropospheric air mass factor contribute the majority of the information to the solution.

Figure 8 shows a sample $\mathrm{NO}_{2}$ model profile and scattering weights for a nadir observation over a polluted area of Houston, as well as the profile and scattering weights for a nearby zenith reference spectrum. Similar stratospheric profiles for the nadir and zenith sky spectra mean that the stratospheric components in Eq. (5) are similar, although the non-zero difference between nadir and zenith scattering weights above the aircraft do indicate that these terms do not entirely cancel. In this illustrated case, $S^{\uparrow}-S_{\mathrm{R}}^{\uparrow}=$ $-5.3 \times 10^{14}$ molecules $\mathrm{cm}^{-2}$. Even though the zenith spectra are often collected over mildly polluted areas during an urban campaign, the small tropospheric zenith reference scattering weights ensure the zenith contribution from the profile is small, with $S_{\mathrm{R}}^{\downarrow}=7.6 \times 10^{14}$ molecules $\mathrm{cm}^{-2}$ for this particular observation. 

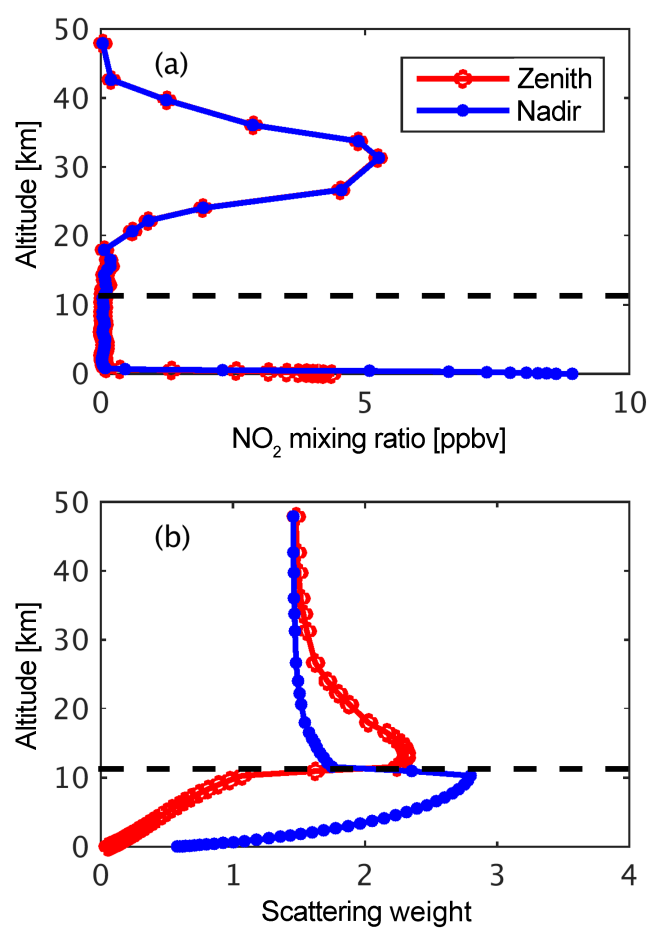

Figure 8. Sample profiles used in AMF calculation for a polluted region on 13 September $201310: 31 \mathrm{LT}$ at $29.51^{\circ} \mathrm{N}$ and $95.34^{\circ} \mathrm{W}$, with a solar zenith angle (SZA) of $47.0^{\circ}$ and a viewing zenith angle (VZA) of $13.2^{\circ}$, showing (a) modeled $\mathrm{NO}_{2}$ mixing ratio profiles for a nadir observation and a nearby zenith observation; and (b) their corresponding scattering weights. The aircraft flight altitude is shown by the black dashed line. The modeled tropospheric $\mathrm{NO}_{2}$ column is $1.1 \times 10^{16}$ molecules $\mathrm{cm}^{-2}$ and the retrieved is $2.1 \times 10^{16}$ molecules $\mathrm{cm}^{-2}$.

\subsection{Uncertainties}

\subsubsection{Slant column uncertainties}

The mean fitting precision of individual $\mathrm{NO}_{2}$ slant column retrievals at native spatial resolution for all flights is $\sim 2.3 \times 10^{16}$ molecules $\mathrm{cm}^{-2}$. The precision of the differential slant column $\mathrm{d} S$ is $\sim 2.2 \times 10^{15}$ molecules $\mathrm{cm}^{-2}$ at $250 \mathrm{~m} \times 250 \mathrm{~m}$ resolution. This varies with scene brightness over Houston by about $\pm 0.4 \times 10^{15}$ molecules $\mathrm{cm}^{-2}$. The fitting precision is larger in cases where the effective footprint is partially obstructed by a cloud and fewer observations are co-added. The GeoTASO design requirement at $1 \mathrm{~km} \times 1 \mathrm{~km}$ resolution derived from TEMPO requirements (Chance et al., 2013) is $1 \times 10^{15}$ molecules $\mathrm{cm}^{-2}$; at $1 \mathrm{~km} \times 1 \mathrm{~km}$ spatial resolution, if errors were Gaussian, the actual precision of $5.5 \times 10^{14}$ molecules $\mathrm{cm}^{-2}$ could exceed the requirement.

Additional uncertainties in the differential slant column result from uncertainties in the $\mathrm{NO}_{2}$ measured cross sections of about $2 \%$ (Boersma et al., 2004) and the use of a cross section at a single temperature. Satellite retrievals typically use $\mathrm{NO}_{2}$ cross sections at lower stratospheric temperatures, which can result in uncertainties as high as $20 \%$ in polluted regions if an empirical correction is not applied (Boersma et al., 2004). GeoTASO retrievals use $\mathrm{NO}_{2}$ cross sections at 294 K. During GeoTASO flight times, surface temperatures were on the order of 296-304 K. The effective temperature of tropospheric $\mathrm{NO}_{2}$ (Brinksma et al., 2002) for measurements with high column $\mathrm{NO}_{2}\left(>3 \times 10^{15}\right.$ molecules $\left.\mathrm{cm}^{-2}\right)$ is typically $275-293 \mathrm{~K}$, which could result in a small high bias in retrieved $\mathrm{NO}_{2}$. The effect of the colder stratospheric $\mathrm{NO}_{2}$ on the results should be minimized by the use of a zenith sky reference.

The differential slant column correction term $\mathrm{d} S_{\mathrm{O}}$ is affected by the same uncertainties in slant column retrievals; however, its effective precision is improved to $7 \times$ $10^{14}$ molecules $\mathrm{cm}^{-2}\left(\mathrm{rms}=5 \times 10^{-3}\right)$ due to averaging of many spectra in the along-track direction.

\subsubsection{Air mass factor and model uncertainties}

Uncertainties in air mass factors typically contribute the largest component of satellite vertical column measurement error budgets in polluted observations (Martin et al., 2002; Boersma et al., 2004). Uncertainties in surface reflectivity, the vertical distribution of aerosols relative to $\mathrm{NO}_{2}$ and trace gas vertical profiles generally dominate air mass factor uncertainties for cloud-free $\mathrm{NO}_{2}$ data. Lawrence et al. (2015) estimated an AMF uncertainty of $\sim 8 \%$ in remotely sensed $\mathrm{NO}_{2}$ from an airborne mission over Leicester, United Kingdom, primarily resulting from uncertainties in the surface albedo and $\mathrm{NO}_{2}$ profile shape.

The AMF in the $\mathrm{NO}_{2}$ region also has some wavelength dependency, and use of an AMF calculated at a single wavelength can lead to slight biases in the vertical columns. For typical $\mathrm{NO}_{2}$ observations, the effects are small; the AMF varies by about $5 \%$ across the $\mathrm{NO}_{2}$ fitting window between 420 and $465 \mathrm{~nm}$. The AMF at the center of the GeoTASO fitting window at $442 \mathrm{~nm}$ is on the order of $3 \%$ smaller than that at $470 \mathrm{~nm}$ (the MODIS BRDF band).

We estimate an uncertainty of $20 \%$ in the MODIS BRDF product for both accuracy and precision, based on comparisons between MODIS BRDF-derived reflectance and aircraft observations at a similar spatial scale to the GeoTASO $250 \mathrm{~m} \times 250 \mathrm{~m}$ observations (Román et al., 2011). The resultant uncertainty in the AMF is about $10 \%$ for polluted scenes and $5 \%$ for clean scenes.

Uncertainties in aerosol distribution can contribute large uncertainties to the AMF, and the presence of aerosols can increase or decrease the AMF, depending on aerosol type and altitude (Leitão et al., 2010). Section 5.1 discusses aerosol optical depth and uncertainties specific to the DISCOVERAQ GeoTASO measurements in greater detail.

Figure 9 shows median $\mathrm{NO}_{2}$ profile shapes derived from CMAQ simulations and in situ P-3B aircraft profiles collected during the campaign at locations of aircraft vertical spirals. These profiles reveal that typical uncertainties in pro- 


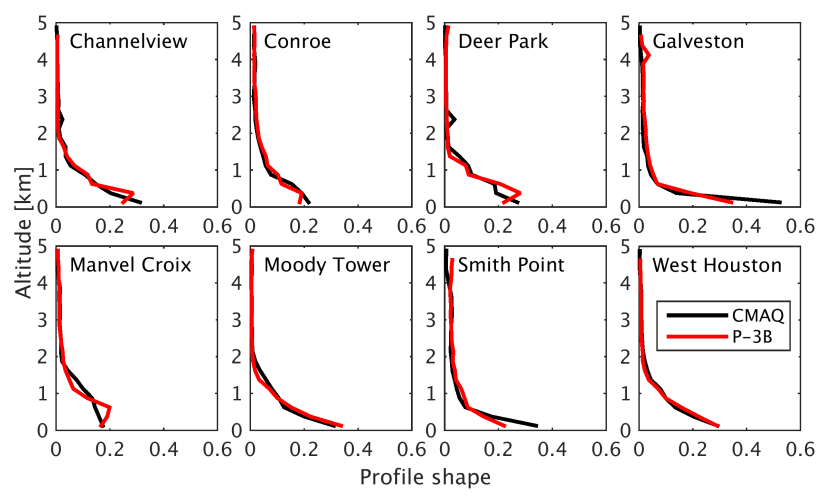

Figure 9. Normalized median profile shapes from CMAQ model simulations and $\mathrm{P}-3 \mathrm{~B}$ aircraft $\mathrm{NO}_{2}$ observations at $\mathrm{P}-3 \mathrm{~B}$ spiral locations during the DISCOVER-AQ Texas campaign. The profiles use model output and observations binned to a $250 \mathrm{~m}$ altitude grid.

file shape factors are generally less than $20 \%$; uncertainties of this magnitude typically result in a $\sim 5 \%$ uncertainty in the AMF below the aircraft. Individual partial column model uncertainties are sometimes much larger $(>100 \%)$ when compared with P-3B profiles, which can contribute a small uncertainty through the term $V_{\mathrm{R}}^{\downarrow}$ in Eq. (7). In addition, we estimate a $30 \%$ uncertainty in $\mathrm{NO}_{2}$ stratospheric columns from the PRATMO model, based on typical differences with OSIRIS limb measurements of $\mathrm{NO}_{2}$ (Bourassa et al., 2011).

Uncertainties in CMAQ surface mixing ratios also directly impact uncertainties in the GeoTASO-inferred surface mixing ratios that will be presented in Sect. 5.2.2. Figure 10 shows the mean bias of CMAQ $\mathrm{NO}_{2}$ relative to surface observations as a function of local time, derived from all sites and over all days during the campaign. Uncertainties in the model surface estimates vary by time of day and are largest in the morning hours. Comparisons between CMAQ surface mixing ratios and the in situ surface $\mathrm{NO}_{2}$ observations during DISCOVER-AQ derived from all sites indicate that uncertainties at 09:00 LT are on the order of $6 \mathrm{ppbv}$, but decrease rapidly by 10:00 LT, with biases $<1 \mathrm{ppbv}$ over most of the flight. Gross error is on the order of 2 ppbv during the most of the GeoTASO flight times.

\subsubsection{Total uncertainty}

We calculate total uncertainty estimates for each observation using the uncertainties in individual column and AMF terms by propagation of errors through Eq. (7). Assuming errors are uncorrelated, we estimate that total uncertainties in $\mathrm{NO}_{2}$ tropospheric columns for relatively clean cloud-free pixels $\left(<0.3 \times 10^{16}\right.$ molecules $\left.\mathrm{cm}^{-2}\right)$ range from $45 \%$ to $>100 \%$. Uncertainties in moderately polluted pixels $\left(0.3-1 \times 10^{16}\right.$ molecules $\left.\mathrm{cm}^{-2}\right)$ range from 30 to $80 \%$, while uncertainties in heavily polluted pixels $(>1 \times$ $10^{16}$ molecules $\mathrm{cm}^{-2}$ ) are $27-40 \%$.

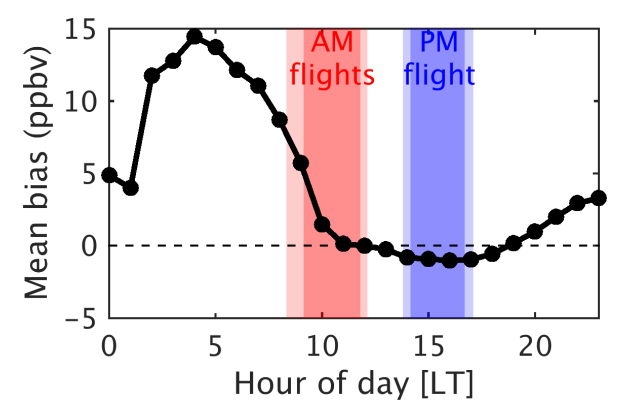

Figure 10. Mean bias in $\mathrm{NO}_{2}$ surface mixing ratio of CMAQ simulations relative to surface observations averaged at all campaign validation sites. The pale pink (a.m.) and blue (p.m.) shadings indicate the time range of GeoTASO flights, while the darker shadings indicate the time range of coincident GeoTASO and surface observations.

\section{Results and validation}

\subsection{Urban $\mathrm{NO}_{2}$ observations}

Figure 11 shows $\mathrm{NO}_{2}$ tropospheric vertical columns derived from GeoTASO during 4 days of DISCOVER-AQ flights over the Houston area. The 13 September was the day with the highest levels of detected $\mathrm{NO}_{2}$ and also the day most free of clouds. Figure 12 shows an enlarged view of the first overpass of this day over urban Houston. In these 13 September flights, the two most polluted overpasses occur over downtown Houston and several large freeways (I-10, I-45, I-69, I-610) and their interchanges. The more southern polluted overpass occurs over the more rural and suburban Route 6, and the Manvel Croix science site. Although there are few local sources of pollution, the suburban Manvel region of Houston regularly has some of the highest ozone concentrations in the Houston area (Sather and Cavender, 2012).

While the majority of $\mathrm{NO}_{2}$ appears correlated with roads and highly populated areas, enhanced levels of $\mathrm{NO}_{2}$ are also detectable over industrial facilities, including those to the east of Houston near the entrance of the Houston ship channel, and the petrochemical manufacturing and petroleum refineries at Texas City near Galveston Bay.

Aerosol optical depths measured by the HSRL lidar on the NASA King Air at $532 \mathrm{~nm}$ and by an Aerosol Robotic Network (AERONET) instrument (http://aeronet.gsfc.nasa.gov/) at Moody Tower at $441 \mathrm{~nm}$ indicate that maximum aerosol optical depths (AOD) were as large as 0.4 on 13 September and 0.7 on 14 September. HSRL data indicate that a smoke plume present at $2-3 \mathrm{~km}$ on the 13th contributed to the larger AOD on this day, and also show significant urban pollution aerosols in the boundary layer. The smoke plume remained on the 14th, but HSRL data indicate that urban pollution aerosols at lower altitudes were the main contributor to the AOD. At these AODs, $\mathrm{NO}_{2}$ AMF biases calculated by Lin et al. (2014) are typically within $\pm 25 \%$. Aerosol AOD 


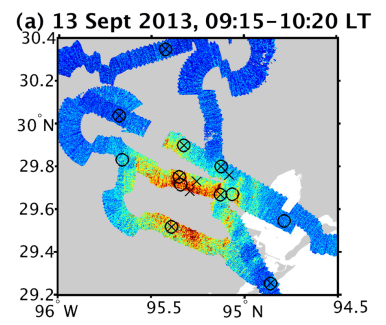

(c) 14 Sept 2013, 14:00-15:30 LT

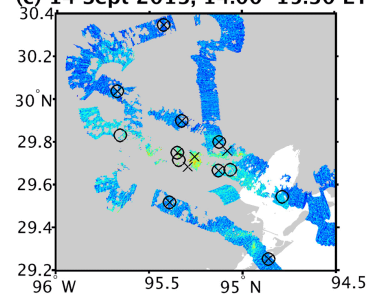

(e) 18 Sept 2013, 09:20-10:40 LT

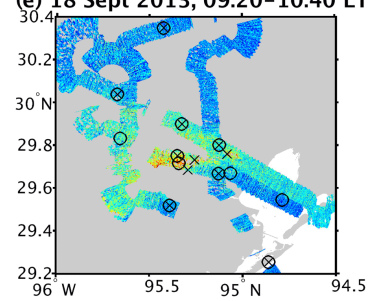

(g) 24 Sept 2013, 10:10-12:00 LT

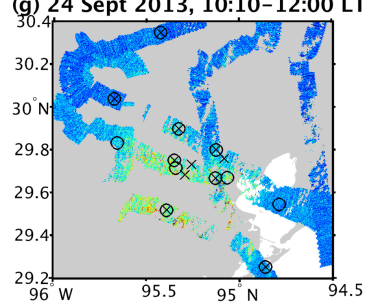

Figure 11. GeoTASO $\mathrm{NO}_{2}$ tropospheric vertical columns at $250 \mathrm{~m} \times 250 \mathrm{~m}$ resolution with a precision of $2.2 \times$ $10^{15}$ molecules $\mathrm{cm}^{-2}$, retrieved for cloud-free observations over Houston during the DISCOVER-AQ campaign. Columns determined from fewer than 20 co-added native pixels (uncertainty $>5 \times 10^{15}$ molecules $\mathrm{cm}^{-2}$ ) are excluded. Locations of DISCOVER-AQ science ground sites are shown with black circles, and locations of TCEQ SLAMS in situ monitors are shown with black crosses.

measured during the 18 and 24 September flights was much smaller $(<0.15)$.

A full assessment of the effects of aerosols on the GeoTASO $\mathrm{NO}_{2}$ air mass factors is beyond the scope of this paper. However, a large of amount of aerosol data collected during the DISCOVER-AQ and the concurrent SEAC4RS (Studies of Emissions, Atmospheric Composition, Clouds and Climate Coupling by Regional Surveys) field campaigns over the southern United States is available for a future detailed study on the effects of aerosols on these aircraft retrievals. These results will be of particular interest when assessed in combination with the independent aerosol retrievals currently under development for GeoTASO (Hou et al., 2016).

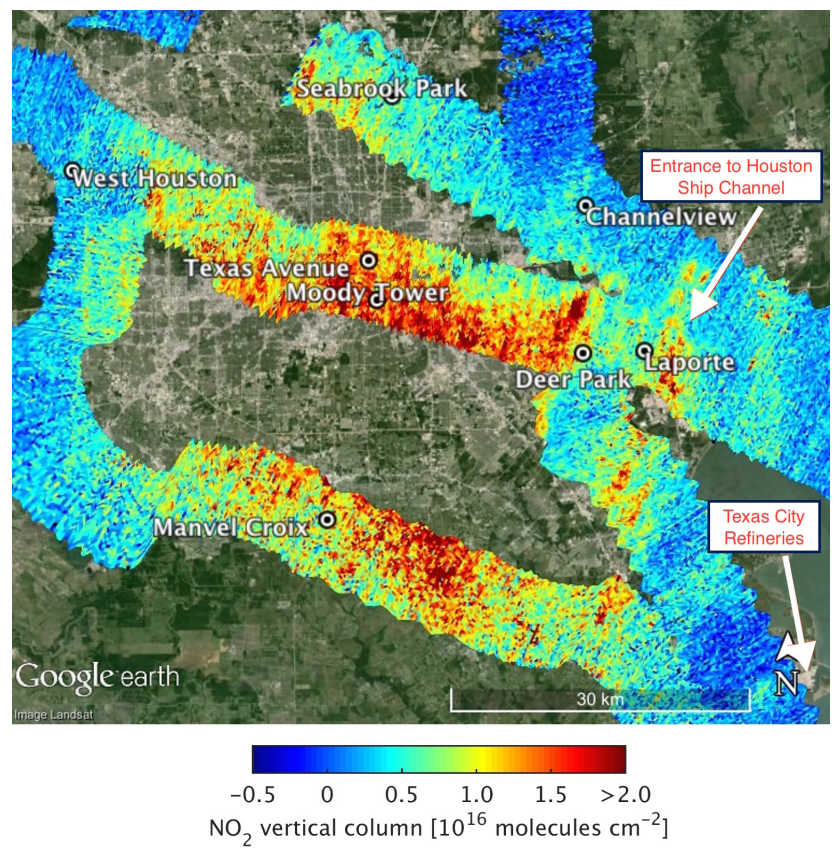

Figure 12. Enlarged view of Fig. 8a showing GeoTASO $\mathrm{NO}_{2}$ tropospheric vertical columns during first Houston overpass on 13 September 2013 and DISCOVER-AQ ground stations in the center of the measurement region. The wave-like pattern in geolocation along the flight track is due to changes in instrument pointing from aircraft roll.

\subsection{Urban $\mathrm{NO}_{2}$ comparisons}

This section presents comparisons of GeoTASO $\mathrm{NO}_{2}$ with observations made from other instruments during the campaign. Table 7 presents a summary of the results of the comparisons with ground-based and airborne instruments which will be discussed in the following sections. Ground-based observations are compared with coincident GeoTASO observations when they fall within GeoTASO's $250 \mathrm{~m} \times 250 \mathrm{~m}$ footprint.

\subsubsection{Ground-based column observations}

Figure 13 shows a comparison between GeoTASO total columns and Pandora total columns measured from the ground. GeoTASO total columns are the sum of the retrieved tropospheric column and the modeled stratospheric column. The stratospheric column is generally on the order of $3 \times 10^{15}$ molecules $\mathrm{cm}^{-2}$ for these observations.

The original 13 September data contain five noticeable measurement outliers, where GeoTASO measures 2-3 times more $\mathrm{NO}_{2}$ than the Pandora spectrometer. Four of these five observations occur at the Moody Tower science site at the University of Houston (the fifth is at the Manvel Croix site), where two Pandora spectrometers made observations of total column above the towers from an altitude of $70 \mathrm{~m}$. At 


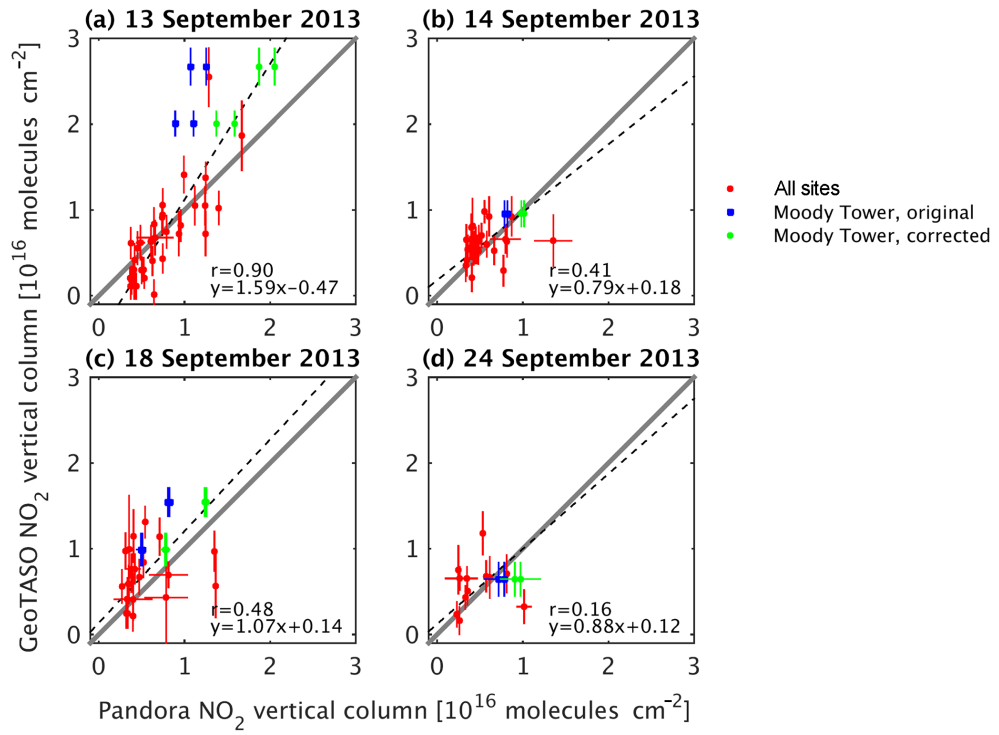

Figure 13. Pandora $\mathrm{NO}_{2}$ vertical columns vs. GeoTASO $\mathrm{NO}_{2}$ total vertical columns (retrieved tropospheric column plus modeled stratospheric column) for cloud-free observations during four Houston urban flights during DISCOVER-AQ 2013. Data collected at the Moody Tower site $(70 \mathrm{~m})$ have been corrected for the partial $\mathrm{NO}_{2}$ column below the tower (see text). GeoTASO error bars represent fitting uncertainties. The gray solid line represents the $1: 1$ ratio. The black dashed line represents a reduced major axis linear regression using all sites, including corrected Moody Tower data.

this downtown location with high levels of $\mathrm{NO}_{2}$, we find that Pandora observations must be corrected for the large partial $\mathrm{NO}_{2}$ column below the tower. The Pandora total column is corrected by the addition of the column below $70 \mathrm{~m}$ as determined from in situ observations collected every $5 \mathrm{~min}$ by the University of Houston from both the top and base of the towers. The in situ observations indicate that $\mathrm{NO}_{2}$ was generally well mixed below $70 \mathrm{~m}$ during these observations, and we determine the partial column from the product of the mean in situ mixing ratio and the CMAQ air column below $70 \mathrm{~m}$. The partial columns below $70 \mathrm{~m}$ can be a significant component of the total column $\left(8.0 \times 10^{15}\right.$ molecules $\mathrm{cm}^{-2}$ during the first GeoTASO overpass and $4.8 \times 10^{15}$ molecules $\mathrm{cm}^{-2}$ during the second on 13 September), and their application leads to significant improvement in the agreement with GeoTASO total columns, although on 13 September GeoTASO columns do remain somewhat high relative to Pandora.

There is a good correlation on 13 September between Pandora and GeoTASO total columns $(r=0.90)$, when $\mathrm{NO}_{2}$ amounts were largest over the measurement sites. Correlations are fair for the less polluted days of 14 and 18 September $(r=0.41$ and $r=0.48)$, while the correlation on 24 September is not statistically significant. The larger range of vertical columns on 13 September relative to other days allowed the observations to be more discernible from measurement noise. Overall, the correlation is $r=0.73$, and several high GeoTASO observations of $\mathrm{NO}_{2}$ on 13 September relative to Pandora total column cause GeoTASO total columns to be about $30 \%$ larger than those of Pandora. This high bias relative to Pandora could be could be due to factors such as different viewing geometry and spatial resolution combined with the spatial inhomogeneity of $\mathrm{NO}_{2}$, instrument vertical sensitivity and air mass factor uncertainties or stratospheric $\mathrm{NO}_{2}$. Aerosol optical depth is relatively high on 13 September, with a smoke plume aloft and urban aerosol in the boundary layer, leading to larger uncertainties in the AMF calculation.

It is also useful to consider these results in light of geostationary validation comparisons, such as those planned for TEMPO. Generally, higher pollution levels result in larger variability and a larger $\mathrm{NO}_{2}$ range, and therefore a higher potential correlation between GeoTASO and coincident ground-based observations. TEMPO will have a much coarser spatial resolution $\left(2.1 \times 4.5 \mathrm{~km}^{2}\right.$ at the center of the field of regard) and a higher precision $(<1 \times$ $10^{15}$ molecules $\mathrm{cm}^{-2}$ ). TEMPO will likely see similar features when compared with surface observations (a correlation that typically increases with an increasing range of $\mathrm{NO}_{2}$ ), but may see a reduced slope, due to coarser spatial resolution, and a reduced correlation coefficient, due to both coarser spatial and temporal resolutions than those of GeoTASO.

\subsubsection{Surface observations}

Of particular interest for satellite missions is the potential to infer surface concentrations from column observations of $\mathrm{NO}_{2}$, which is useful for air quality applications and can be validated using relatively dense in situ data networks. Several applied studies have used the method of Lamsal et al. 


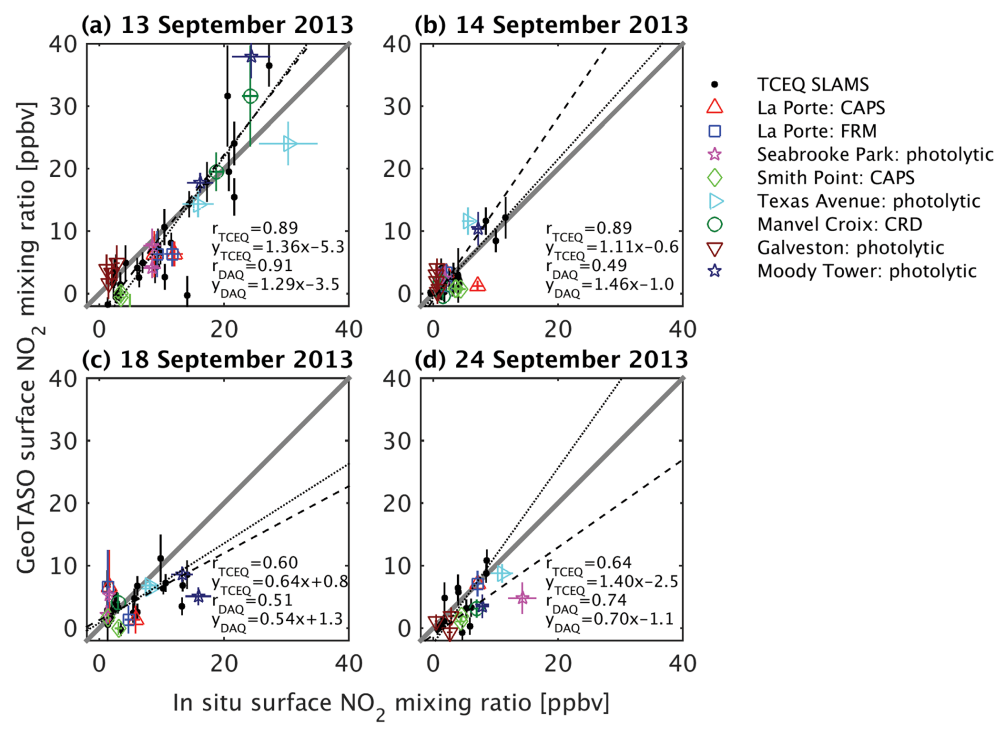

Figure 14. In situ surface $\mathrm{NO}_{2}$ mixing ratios from the TCEQ SLAMS network and DISCOVER-AQ campaign research instrumentation vs. inferred surface $\mathrm{NO}_{2}$ mixing ratios from GeoTASO for cloud-free observations during four Houston urban flights during DISCOVER-AQ 2013. Correlation coefficients and regression results are shown for TCEQ monitors (TCEQ) and for the CAPS, photolytic converter and CRD monitors deployed during DISCOVER-AQ (DAQ). GeoTASO error bars represent fitting uncertainties. The gray line represents the $1: 1$ ratio. The black dashed (DISCOVER-AQ sites) and black dotted (TCEQ SLAMS) lines represent reduced major axis linear regressions.

(2008) to examine exposure, emission sources and deposition (Bechle et al., 2013; Lamsal et al., 2013; McLinden et al., 2014; Nowlan et al., 2014). This approach uses OMI NO columns in combination with a chemical transport model to infer $\mathrm{OMI}$ surface $\mathrm{NO}_{2}$, and has been validated using surface in situ data (Lamsal et al., 2008, 2010, 2015).

We apply this method to infer surface concentrations $S_{\mathrm{GT}}$ using GeoTASO $\mathrm{NO}_{2}$ tropospheric columns and the CMAQ model profiles. This is done by scaling the lowermost CMAQ surface concentration $S_{\mathrm{CMAQ}}(\sim 11 \mathrm{~m}$ altitude) by the ratio of the GeoTASO tropospheric column $V_{\mathrm{GT}}$ to the CMAQ tropospheric column $V_{\mathrm{CMAQ}}$ using

$S_{\mathrm{GT}}=S_{\mathrm{CMAQ}} \frac{V_{\mathrm{GT}}}{V_{\mathrm{CMAQ}}}$.

Figure 14 shows a comparison of inferred GeoTASO surface concentrations with in situ data collected at the surface, for both the TCEQ SLAMS network and science instruments deployed during the DISCOVER-AQ campaign. The polluted 13 September day shows very good correlation between the GeoTASO data and both the TCEQ and campaign science instrumentation ( $r=0.89$ and 0.91 respectively). Biases are generally about $30 \%$. The agreement is quite good with the Texas Avenue photolytic, Moody Tower photolytic and Manvel Croix CRD instruments, which measure the largest $\mathrm{NO}_{2}$ concentrations on 13 September. Correlations between GeoTASO and the TCEQ sites are quite good on other days ( $r=$ 0.60-0.89), while correlations with DISCOVER-AQ in situ instrumentation are slightly lower $(r=0.49-0.74)$, mostly due to fewer coincident observations at high $\mathrm{NO}_{2}$ values.
All surface in situ correlations are significant at the $p<0.05$ level, with the exception of DISCOVER-AQ observations on 18 September. Overall, both TCEQ and DISCOVER-AQ observations are well correlated with GeoTASO surface estimates $(r=0.85)$, with GeoTASO $14 \%$ higher than in situ observations at locations of elevated $\mathrm{NO}_{2}$.

Several factors can lead to observed differences between GeoTASO and in situ observations, in addition to the uncertainties discussed in Sects. 4.6 and 5.2.1. Biases in CMAQ surface concentrations can propagate to GeoTASO-inferred concentrations. On most days, inferred GeoTASO surface concentrations at low ambient $\mathrm{NO}_{2}$ concentrations are biased low relative to the in situ observations. CMAQ surface concentrations at background levels are similarly biased low relative to the in situ observations on these days, and the bias propagates to the derived GeoTASO surface concentrations. In addition, comparisons may be artificially improved by the fact that the correlation between the model surface concentration and vertical column may be greater than the correlation between the "true" in situ observed concentration at the surface and the profile (observed by the P-3B instruments). Flynn et al. (2014) found that CMAQ profiles during the DISCOVER-AQ Maryland 2011 campaign tended to be more well mixed with altitude than the $\mathrm{P}-3 \mathrm{~B}$ profiles. $\mathrm{NO}_{2}$ temporal variability and inhomogeneity within an aircraft footprint can also play a large role in uncertainties when aircraft observations are compared with in situ observations at urban locations. For instance, the Moody Tower in situ observations on 18 September varied between 5 and 45 ppbv within $10 \mathrm{~min}$ of the second GeoTASO overpass. 
Table 7. Summary of $\mathrm{NO}_{2}$ comparisons between Pandora total column observations, in situ surface validation mixing ratios and GCAS aircraft slant columns with GeoTASO observations.

\begin{tabular}{|c|c|c|c|c|c|}
\hline & 13 September & 14 September & 18 September & 24 September & All dates \\
\hline \multicolumn{6}{|l|}{ Pandora total column } \\
\hline$N$ & 39 & 35 & 31 & 21 & 136 \\
\hline$r$ & 0.90 & 0.41 & 0.48 & 0.16 & 0.73 \\
\hline$p$ value & $<0.001$ & 0.01 & 0.01 & 0.57 & $<0.001$ \\
\hline Slope & 1.59 & 0.79 & 1.07 & 0.88 & 1.31 \\
\hline Intercept $\left(10^{16}\right.$ molecules $\left.\mathrm{cm}^{-2}\right)$ & -0.47 & 0.18 & 0.14 & 0.12 & -0.13 \\
\hline \multicolumn{6}{|l|}{ TCEQ surface sites } \\
\hline$N$ & 26 & 23 & 21 & 12 & 82 \\
\hline$r$ & 0.89 & 0.89 & 0.60 & 0.64 & 0.85 \\
\hline$p$ value & $<0.001$ & $<0.001$ & 0.004 & 0.03 & $<0.001$ \\
\hline Slope & 1.36 & 1.11 & 0.64 & 1.40 & 1.14 \\
\hline Intercept (ppbv) & -5.3 & -0.6 & 0.8 & -2.5 & -1.9 \\
\hline \multicolumn{6}{|l|}{ DISCOVER-AQ surface sites } \\
\hline$N$ & 17 & 16 & 11 & 10 & 54 \\
\hline$r$ & 0.91 & 0.49 & 0.51 & 0.74 & 0.85 \\
\hline$p$ value & $<0.001$ & 0.05 & 0.11 & 0.02 & $<0.001$ \\
\hline Slope & 1.29 & 1.46 & 0.54 & 0.70 & 1.14 \\
\hline Intercept (ppbv) & -3.5 & -1.0 & 1.3 & -1.1 & -1.8 \\
\hline \multicolumn{6}{|l|}{ GCAS slant column } \\
\hline$N$ & 48555 & 929 & 18111 & 9725 & 77320 \\
\hline$r$ & 0.84 & 0.25 & 0.72 & 0.53 & 0.81 \\
\hline$p$ value & $<0.001$ & $<0.001$ & $<0.001$ & $<0.001$ & $<0.001$ \\
\hline Slope & 0.94 & 1.41 & 0.82 & 1.24 & 0.91 \\
\hline Intercept $\left(10^{16}\right.$ molecules $\left.\mathrm{cm}^{-2}\right)$ & -0.01 & 0.03 & -0.08 & -0.01 & -0.02 \\
\hline
\end{tabular}

$N$ : number of coincident measurements

$r$ : correlation coefficient

slope and intercept: results of reduced major axis linear regression of observations vs. GeoTASO.

\subsubsection{Aircraft observations}

The NASA Falcon made several flights coincident with the NASA King Air B200 carrying the GCAS instrument during the campaign. In this section we present comparisons with preliminary $\mathrm{NO}_{2}$ retrievals from the GCAS instrument, which was also participating in its first field campaign since its modification from the ACAM instrument. As summarized in Table 7, the 13 September flights had the largest number of coincident observations. This was due to cloud-free conditions and tight flight coincidences in space and time. Figure 15 shows GCAS (King Air B200 flying at $9 \mathrm{~km}$ )- and GeoTASO (NASA Falcon flying at $11.3 \mathrm{~km}$ )-retrieved $\mathrm{NO}_{2}$ slant columns for the first overpass of Houston on 13 September 2013 at the GCAS resolution of $250 \mathrm{~m} \times 500 \mathrm{~m}$. These GeoTASO slant columns correspond to those data shown in Fig. 11a, before the AMF is applied.

The GeoTASO fitting algorithm is used to retrieve GCAS slant columns, with identical fitting parameters and wavelength region. The GCAS retrievals use a single mean nadir
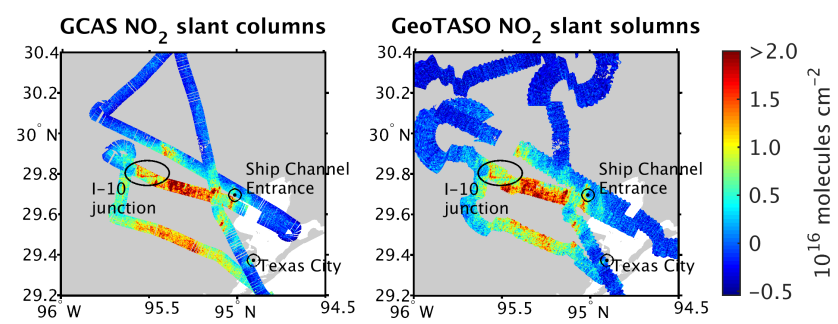

Figure 15. GCAS and GeoTASO retrieved $\mathrm{NO}_{2}$ slant columns at $250 \mathrm{~m} \times 500 \mathrm{~m}$ resolution during their first Houston overpasses on 13 September 2013 between 09:00 and 10:20 LT (LT $=$ UTC -5 h).

reference spectrum collected during a pass over the relatively clean Gulf of Mexico. Like GeoTASO, the retrieved GCAS slant columns also show a persistent background offset. However, in the case of GCAS, we did not find striping as with GeoTASO, but rather that the offset varied smoothly across the field of view from 0 to $1.5 \times 10^{16}$ molecules $\mathrm{cm}^{-2}$. The derived offset is removed from the GCAS slant columns 

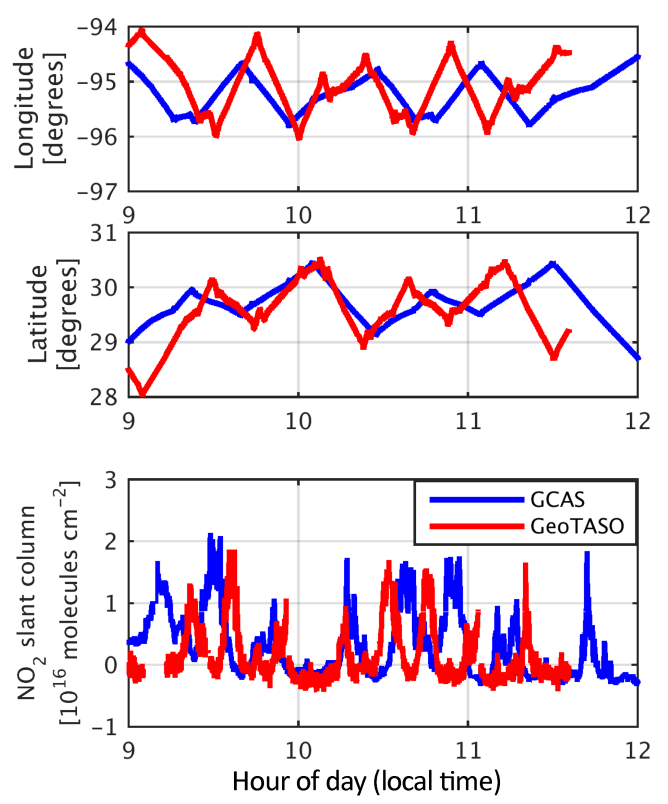

Figure 16. GCAS and GeoTASO (a) longitude; (b) latitude; and (c) retrieved $\mathrm{NO}_{2}$ slant column as a function of time during the two morning 13 September 2013 Houston overpasses.

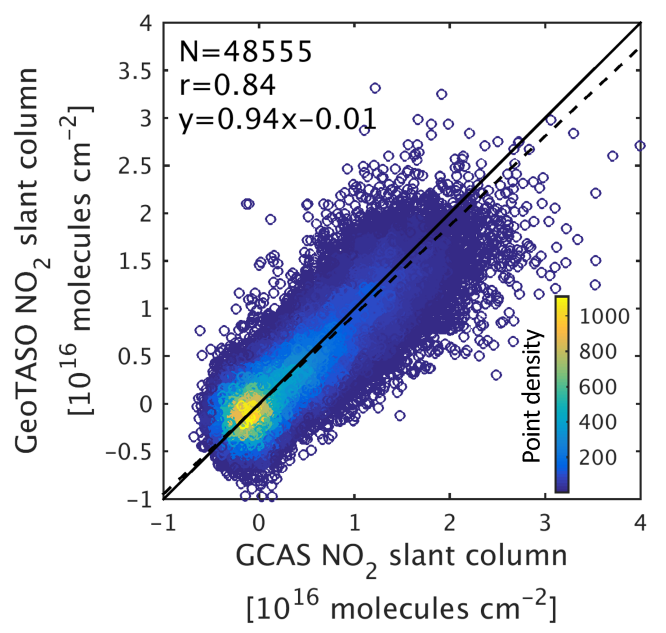

Figure 17. GCAS vs. GeoTASO retrieved $\mathrm{NO}_{2}$ slant columns during the two morning 13 September 2013 Houston overpasses for nearest coincident observations within $10 \mathrm{~min}$ and $500 \mathrm{~m}$. The black solid line represents the $1: 1$ ratio. The black dashed line represents a reduced major axis linear regression.

in the data presented in this section, with a correction applied for background slant column density derived from the CMAQ model.

Figure 16 shows the GCAS and GeoTASO geolocation data and $\mathrm{NO}_{2}$ slant columns averaged across track as a function of local time during the two morning overpasses. The offset in geolocation vs. time between the two aircraft is clearly visible in the $\mathrm{NO}_{2}$ peaks. At the beginning of the

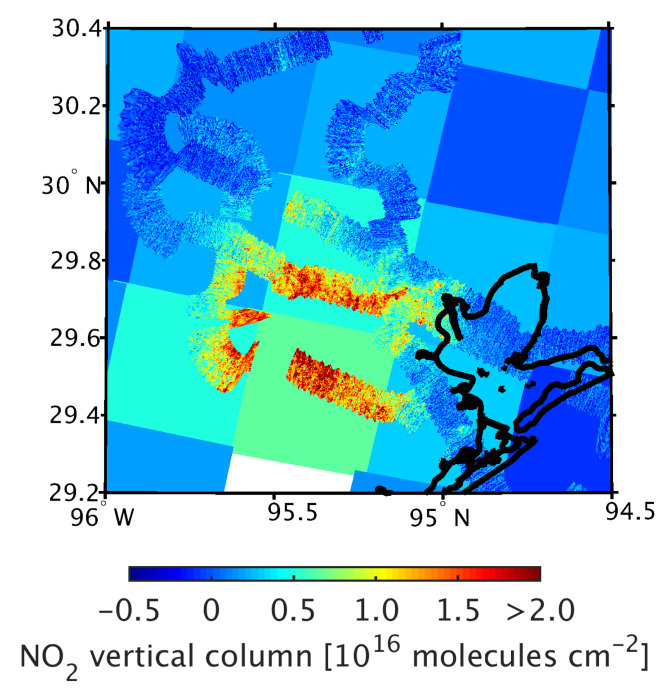

Figure 18. GeoTASO $\mathrm{NO}_{2}$ tropospheric vertical columns at $250 \mathrm{~m} \times 250 \mathrm{~m}$ resolution from 10:20 to $11: 30 \mathrm{LT}$, retrieved for cloud-free observations on 13 September plotted over GOME2/Metop-A tropospheric vertical columns where radiative cloud fraction is less than 0.5 .

overpass, GeoTASO was measuring approximately $10 \mathrm{~min}$ after GCAS, but just after 10:00 LT the Falcon aircraft overtook the King Air, and the later $\mathrm{NO}_{2}$ observations are shifted by as much as $20 \mathrm{~min}$. Figure 17 shows the GCAS slant column plotted vs. its closest GeoTASO coincidence within $10 \mathrm{~min}$ and $500 \mathrm{~m}$. On 13 September, the slant columns are well correlated $(r=0.84)$ and agree well in magnitude, with GeoTASO slant columns on average about $6 \%$ less than GCAS slant columns. Overall, data from all days result in a correlation of $r=0.81$, with GeoTASO $9 \%$ lower than GCAS. The comparisons remain similar for tighter coincidence criteria.

On the whole, slant columns between the two instruments agree very well in magnitude, although there are some differences. For instance, in Fig. 15, the southernmost flight legs, which occurred early in the flight (over Manvel Croix, south of downtown Houston), show some differences in $\mathrm{NO}_{2}$ distribution between the two instruments which is likely due to highly variable $\mathrm{NO}_{2}$ and slightly different overpass times. Several local sources are easily detectable in both instruments, including petrochemical manufacturing and refining facilities in Texas City and near the Houston Ship Channel. Both instruments show a clear enhancement in $\mathrm{NO}_{2}$ over the junction of two large highways to the west of Houston's center: the I-10 and the Sam Houston Parkway ring road. Interestingly, although $\mathrm{NO}_{2}$ is still detectable over those roads in the vertical column in Fig. 11, its abundance relative to other areas decreases significantly after the MODIS BRDF has been applied at high spatial resolution, which attempts to account for the effect of surface reflectivity on the retrievals, as these particular highways are flanked by bright buildings 
bordering darker forests and fields which cause their slant columns to be particularly pronounced relative to their surroundings.

\subsubsection{Satellite observations}

The only GeoTASO Houston flight that had coincident cloud-free satellite observations was the second Houston overpass on 13 September 2013, which occurred during a GOME-2/Metop-A observation of the Houston area at 11:00 LT. (The 14 September flight had a coincident overpass of OMI, but the OMI data are cloudy over the flight area.) Figure 18 shows the GeoTASO $\mathrm{NO}_{2}$ tropospheric column plotted over the $40 \mathrm{~km} \times 40 \mathrm{~km}$ GOME- 2 tropospheric columns for this overpass, and illustrates the potential inhomogeneity within a GOME-2 ground pixel. The precision of these GOME-2 $\mathrm{NO}_{2}$ tropospheric columns is about $1 \times 10^{15}$ molecules $\mathrm{cm}^{-2}$. A quantitative comparison of the two retrievals is made difficult by the geographic distribution of the GeoTASO data and very different spatial resolutions; however, enhancements in GOME- $2 \mathrm{NO}_{2}$ are consistent with large GeoTASO columns, and mean values are reasonable considering the obvious spatial variability in $\mathrm{NO}_{2}$ within a GOME-2 pixel.

\section{Summary and conclusions}

We have presented the first trace gas retrieval results from the GeoTASO airborne instrument using data collected during the DISCOVER-AQ field campaign based in Houston, Texas, during September 2013. We first retrieve differential $\mathrm{NO}_{2}$ slant columns from the ratio of GeoTASO cloud-free nadir spectra to a mean zenith sky reference spectrum and co-added to $250 \mathrm{~m} \times 250 \mathrm{~m}$ resolution after a cross-track striping correction, with a resultant precision of $\pm 2.2 \times 10^{15}$ molecules $\mathrm{cm}^{-2}$. We then determine vertical columns below the aircraft from slant columns using air mass factors derived from a radiative transfer calculation with tropospheric profiles from the CMAQ model and high-resolution MODIS surface BRDFs. Total uncertainties in moderately polluted $\mathrm{NO}_{2}$ vertical columns $\left(0.3-1 \times 10^{16}\right.$ molecules $\left.\mathrm{cm}^{-2}\right)$ are in the range of 30 $80 \%$, while uncertainties in heavily polluted columns (> $1 \times 10^{16}$ molecules $\mathrm{cm}^{-2}$ ) vary from 27 to $40 \%$.

Data from the overflights of Houston show good agreement with ground-based observations. Comparisons with total column $\mathrm{NO}_{2}$ measured by ground-based Pandora spectrometers show good agreement overall, with $r=0.73$ for all four measurement days during the campaign. The correlation is very good $(r=0.90)$ for the most polluted day with the largest range of elevated $\mathrm{NO}_{2}$ columns. Little bias is observed except for a slight overestimation of $\mathrm{NO}_{2}$ by GeoTASO relative to the Pandora instrument at the very highest $\mathrm{NO}_{2}$ columns $\left(>2 \times 10^{16}\right.$ molecules $\left.\mathrm{cm}^{-2}\right)$. We also infer surface mixing ratios by scaling the ratio of CMAQ-modeled
$\mathrm{NO}_{2}$ surface mixing ratios by the ratio of GeoTASO column to the modeled column. These GeoTASO-inferred surface mixing ratios correlate well with "true" $\mathrm{NO}_{2}$ mixing ratios measured in situ at the surface during the campaign, with $r=0.85$ for comparisons with both the TCEQ SLAMS network and DISCOVER-AQ campaign instrumentation. Overall, GeoTASO-inferred surface $\mathrm{NO}_{2}$ is $14 \%$ larger than mixing ratios measured in situ.

Preliminary slant column retrievals from the GCAS instrument on the King Air B200 aircraft agree well in magnitude and distribution with GeoTASO observations taken close in time $(r=0.81$ and slope $=0.91)$. We also present an overpass of GOME-2 $\mathrm{NO}_{2}$. Even though direct comparison is difficult with the satellite data due to the geographic distribution of GeoTASO observations, the spatial distribution and magnitude of the $\mathrm{NO}_{2}$ columns are reasonable.

Future work with GeoTASO trace gas retrievals will involve further analysis of GeoTASO data from the Colorado DISCOVER-AQ campaign, where the instrument flew on a number of flights, as well as validation of other molecules absorbing in the ultraviolet. GeoTASO also participated as a component of NASA's contribution to the KORUS-AQ air quality field campaign over the Republic of Korea in 2016.

\section{Data availability}

GeoTASO trace gas products are available from the DISCOVER-AQ data archive at http://www-air.larc.nasa. gov/missions/discover-aq/discover-aq.html.

Acknowledgements. This work was supported under the NASA Earth Science Technology Office (ESTO) Instrument Incubator Program and the NASA GEO-CAPE Program. MODIS MCD43GF V005 data were provided by the MODIS remote sensing group at the University of Massachusetts, Boston. We acknowledge the free use of tropospheric $\mathrm{NO}_{2}$ column data from GOME-2/Metop-A from http://www.temis.nl. The US Environmental Protection Agency through its Office of Research and Development under the Air, Climate and Energy Research Program collaborated on this research. It has been subjected to agency review and approved for publication.

Edited by: F. Boersma

\section{References}

Appel, W., Gilliam, R., Pleim, J., Pouliot, G., Wong, D.-C., Hogrefe, C., Roselle, S., and Mathur, R.: Improvements to the WRF-CMAQ modeling system for fine-scale air quality simulations, EM Magazine, 14 September 2014, 16-21, 2014.

Bechle, M. J., Millet, D. B., and Marshall, J. D.: Remote sensing of exposure to $\mathrm{NO}_{2}$ : Satellite versus ground-based measurement in a large urban area, Atmos. Environ., 69, 345-353, doi:10.1016/j.atmosenv.2012.11.046, 2013. 
Boersma, K. F., Eskes, H. J., and Brinksma, E. J.: Error analysis for tropospheric $\mathrm{NO}_{2}$ retrieval from space, J. Geophys. Res.-Atmos., 109, D04311, doi:10.1029/2003JD003962, 2004.

Boersma, K. F., Eskes, H. J., Dirksen, R. J., van der A, R. J., Veefkind, J. P., Stammes, P., Huijnen, V., Kleipool, Q. L., Sneep, M., Claas, J., Leitão, J., Richter, A., Zhou, Y., and Brunner, D.: An improved tropospheric $\mathrm{NO}_{2}$ column retrieval algorithm for the Ozone Monitoring Instrument, Atmos. Meas. Tech., 4, 19051928, doi:10.5194/amt-4-1905-2011, 2011.

Bourassa, A. E., McLinden, C. A., Sioris, C. E., Brohede, S., Bathgate, A. F., Llewellyn, E. J., and Degenstein, D. A.: Fast $\mathrm{NO}_{2}$ retrievals from Odin-OSIRIS limb scatter measurements, Atmos. Meas. Tech., 4, 965-972, doi:10.5194/amt-4-965-2011, 2011.

Brent, L. C., Thorn, W. J., Gupta, M., Leen, B., Stehr, J. W., He, H., Arkinson, H. L., Weinheimer, A., Garland, C., Pusede, S. E., Wooldridge, P. J., Cohen, R. C., and Dickerson, R. R.: Evaluation of the use of a commercially available cavity ringdown absorption spectrometer for measuring $\mathrm{NO}_{2}$ in flight, and observations over the Mid-Atlantic States, during DISCOVER-AQ, J. Atmos. Chem., 72, 1-19, doi:10.1007/s10874-013-9265-6, 2013.

Brinksma, E., de Haan, J., Boersma, F., Bucsela, E., and Gleason, J. F.: Appendix A: Air mass factors over polluted scenes, in: OMI Algorithm Theoretical Basis Document, Volume IV: OMI Trace Gas Algorithms, edited by: Chance, K., NASA GSFC, Greenbelt, MD, USA, 29-32, 2002.

Brion, J., Chakir, A., Daumont, D., Malicet, J., and Parisse, C.: High-resolution laboratory absorption cross section of $\mathrm{O}_{3}$, Temperature effect, Chem. Phys. Lett., 213, 610-612, 1993.

Bucsela, E. J., Krotkov, N. A., Celarier, E. A., Lamsal, L. N., Swartz, W. H., Bhartia, P. K., Boersma, K. F., Veefkind, J. P., Gleason, J. F., and Pickering, K. E.: A new stratospheric and tropospheric $\mathrm{NO}_{2}$ retrieval algorithm for nadir-viewing satellite instruments: applications to OMI, Atmos. Meas. Tech., 6, 26072626, doi:10.5194/amt-6-2607-2013, 2013.

Byun, D. and Schere, K. L.: Review of the governing equations, computational algorithms, and other components of the Models3 Community Multiscale Air Quality (CMAQ) modeling system, Appl. Mech. Rev., 59, 51-77, doi:10.1115/1.2128636, 2006.

Cai, Z., Liu, Y., Liu, X., Chance, K., Nowlan, C. R., Lang, R., Munro, R., and Suleiman, R.: Characterization and correction of global ozone monitoring experiment 2 ultraviolet measurements and application to ozone profile retrievals, J. Geophys. Res.-Atmos., 117, D07305, doi:10.1029/2011JD017096, 2012.

Chan Miller, C., Gonzalez Abad, G., Wang, H., Liu, X., Kurosu, T., Jacob, D. J., and Chance, K.: Glyoxal retrieval from the Ozone Monitoring Instrument, Atmos. Meas. Tech., 7, 38913907, doi:10.5194/amt-7-3891-2014, 2014.

Chance, K. and Kurucz, R. L.: An improved high-resolution solar reference spectrum for Earth's atmosphere measurements in the ultraviolet, visible, and near infrared, J. Quant. Spectrosc. Ra., 111, 1289-1295, doi:10.1016/j.jqsrt.2010.01.036, 2010.

Chance, K.: Analysis of BrO measurements from the Global Ozone Monitoring Experiment, Geophys. Res. Lett., 25, 3335-3338, 1998.

Chance, K., Palmer, P. I., Spurr, R. J., Martin, R. V., Kurosu, T. P., and Jacob, D. J.: Satellite observations of formaldehyde over North America from GOME, Geophys. Res. Lett., 27, 34613464, 2000.
Chance, K., Kurosu, T. P., and Sioris, C. E.: Undersampling correction for array detector-based satellite spectrometers, Appl. Optics, 44, 1296-1304, doi:10.1364/AO.44.001296, 2005.

Chance, K., Liu, X., Suleiman, R. M., Flittner, D. E., Al-Saadi, J., and Janz, S. J.: Tropospheric emissions: monitoring of pollution (TEMPO), Proc. SPIE 8866, Earth Observing Systems XVIII, 8866, 88660D-1-88660D-16, doi:10.1117/12.2024479, 2013.

Chance, K. V. and Spurr, R. J. D.: Ring effect studies: Rayleigh scattering, including molecular parameters for rotational Raman scattering, and the Fraunhofer spectrum, Appl. Optics, 36, 52245230, 1997.

Fishman, J., Iraci, L. T., Al-Saadi, J., Chance, K., Chavez, F., Chin, M., Coble, P., Davis, C., DiGiacomo, P. M., Edwards, D., Eldering, A., Goes, J., Herman, J., Hu, C., Jacob, D. J., Jordan, C., Kawa, S. R., Key, R., Liu, X., Lohrenz, S., Mannino, A., Natraj, V., Neil, D., Neu, J., Newchurch, M., Pickering, K., Salisbury, J., Sosik, H., Subramaniam, A., Tzortziou, M., Wang, J., and Wang, M.: The United States' next generation of atmospheric composition and coastal ecosystem measurements: NASA's geostationary coastal and air pollution events (GEO-CAPE) mission, B. Am. Meteorol. Soc., 93, 1547-1566, doi:10.1175/bams-d-11-00201.1, 2012.

Flynn, C. M., Pickering, K. E., Crawford, J. H., Lamsal, L., Krotkov, N., Herman, J., Weinheimer, A., Chen, G., Liu, X., Szykman, J., Tsay, S.-C., Loughner, C., Hains, J., Lee, P., Dickerson, R. R., Stehr, J. W., and Brent, L.: Relationship between column-density and surface mixing ratio: Statistical analysis of $\mathrm{O}_{3}$ and $\mathrm{NO}_{2}$ data from the July 2011 Maryland DISCOVER-AQ mission, Atmos. Environ., 92, 429-441, doi:10.1016/j.atmosenv.2014.04.041, 2014.

General, S., Pöhler, D., Sihler, H., Bobrowski, N., Frieß, U., Zielcke, J., Horbanski, M., Shepson, P. B., Stirm, B. H., Simpson, W. R., Weber, K., Fischer, C., and Platt, U.: The Heidelberg Airborne Imaging DOAS Instrument (HAIDI) - a novel imaging DOAS device for 2-D and 3-D imaging of trace gases and aerosols, Atmos. Meas. Tech., 7, 3459-3485, doi:10.5194/amt7-3459-2014, 2014.

González Abad, G., Liu, X., Chance, K., Wang, H., Kurosu, T. P., and Suleiman, R.: Updated Smithsonian Astrophysical Observatory Ozone Monitoring Instrument (SAO OMI) formaldehyde retrieval, Atmos. Meas. Tech., 8, 19-32, doi:10.5194/amt-8-192015, 2015a.

González Abad, G., Vasilkov, A., Seftor, C., Liu, X., and Chance, K.: Smithsonian Astrophysical Observatory Ozone Mapping and Profiler Suite (SAO OMPS) formaldehyde retrieval, Atmos. Meas. Tech. Discuss., 8, 9209-9240, doi:10.5194/amtd-8-92092015, 2015b.

Hair, J. W., Hostetler, C. A., Cook, A. L., Harper, D. B., Ferrare, R. A., Mack, T. L., Welch, W., Izquierdo, L. R., and Hovis, F. E.: Airborne high spectral resolution lidar for profiling aerosol optical properties, Appl. Optics, 47, 6734-6752, doi:10.1364/AO.47.006734, 2008.

Herman, J., Cede, A., Spinei, E., Mount, G., Tzortziou, M., and Abuhassan, N.: $\mathrm{NO}_{2}$ column amounts from groundbased Pandora and MFDOAS spectrometers using the directsun DOAS technique: Intercomparisons and application to OMI validation, J. Geophys. Res.-Atmos., 114, D13307, doi:10.1029/2009JD011848, 2009. 
Heue, K.-P., Wagner, T., Broccardo, S. P., Walter, D., Piketh, S. J., Ross, K. E., Beirle, S., and Platt, U.: Direct observation of two dimensional trace gas distributions with an airborne Imaging DOAS instrument, Atmos. Chem. Phys., 8, 6707-6717, doi:10.5194/acp-8-6707-2008, 2008.

Hou, W., Wang, J., Xu, X., Reid, J. S., and Han, D.: VLIDORT: An algorithm for hyperspectral remote sensing of aerosols: 1 . Development of theoretical framework, J. Quant. Spectrosc. Ra., 178, 400-415, doi:10.1016/j.jqsrt.2016.01.019, 2016.

Illing, R. M. E.: Design and development of the PolZero Time Domain Polarization Scrambler, Proc. SPIE, 7461, Polarization Science and Remote Sensing IV, 746104-1-746104-10, doi:10.1117/12.826217, 2009.

Ingmann, P., Veihelmann, B., Langen, J., Lamarre, D., Stark, H., and Courrèges-Lacoste, G. B.: Requirements for the GMES atmosphere service and ESA's implementation concept: Sentinels-4/-5 and-5p, Remote Sens. Environ., 120, 58-69, doi:10.1016/j.rse.2012.01.023, 2012.

Kim, J.: GEMS (Geostationary Environment Monitoring Spectrometer) onboard the GeoKOMPSAT to Monitor Air Quality in high Temporal and Spatial Resolution over Asia-Pacific Region, in: EGU General Assembly Conference Abstracts, edited by: Abbasi, A. and Giesen, N., Vol. 14, EGU General Assembly Conference Abstracts, 22-27 April 2012, Vienna, Austria, p. 4051, 2012.

Kowalewski, M. G. and Janz, S. J.: Remote sensing capabilities of the GEO-CAPE airborne simulator, Proc. SPIE, 9218, Earth Observing Systems XIX, 92181I-92181I-12, doi:10.1117/12.2062058, 2014.

Lamsal, L. N., Martin, R. V., Van Donkelaar, A., Steinbacher, M., Celarier, E. A., Bucsela, E., Dunlea, E. J., and Pinto, J. P.: Ground-level nitrogen dioxide concentrations inferred from the satellite-borne Ozone Monitoring Instrument, J. Geophys. Res.Atmos., 113, D16308, doi:10.1029/2007JD009235, 2008.

Lamsal, L. N., Martin, R. V., Van Donkelaar, A., Celarier, E. A., Bucsela, E. J., Boersma, K. F., Dirksen, R., Luo, C., and Wang, Y.: Indirect validation of tropospheric nitrogen dioxide retrieved from the OMI satellite instrument: Insight into the seasonal variation of nitrogen oxides at northern midlatitudes, J. Geophys. Res.-Atmos., 115, D05302, doi:10.1029/2009JD013351, 2010.

Lamsal, L. N., Martin, R. V., Parrish, D. D., and Krotkov, N. A.: Scaling relationship for $\mathrm{NO}_{2}$ pollution and urban population size: a satellite perspective, Environ. Sci. Technol., 47, 78557861, doi:10.1021/es400744g, 2013.

Lamsal, L. N., Duncan, B. N., Yoshida, Y., Krotkov, N. A., Pickering, K. E., Streets, D. G., and Lu, Z.: U. S. $\mathrm{NO}_{2}$ trends (2005-2013): EPA Air Quality System (AQS) data versus improved observations from the Ozone Monitoring Instrument (OMI), Atmos. Environ., 110, 130-143, doi:10.1016/j.atmosenv.2015.03.055, 2015.

Lawrence, J. P., Anand, J. S., Vande Hey, J. D., White, J., Leigh, R. R., Monks, P. S., and Leigh, R. J.: High-resolution measurements from the airborne Atmospheric Nitrogen Dioxide Imager (ANDI), Atmos. Meas. Tech., 8, 4735-4754, doi:10.5194/amt-84735-2015, 2015.

Leitão, J., Richter, A., Vrekoussis, M., Kokhanovsky, A., Zhang, Q. J., Beekmann, M., and Burrows, J. P.: On the improvement of $\mathrm{NO}_{2}$ satellite retrievals - aerosol impact on the airmass factors,
Atmos. Meas. Tech., 3, 475-493, doi:10.5194/amt-3-475-2010, 2010.

Leitch, J. W., Delker, T., Good, W., Ruppert, L., Murcray, F., Chance, K., Liu, X., Nowlan, C., Janz, S. J., Krotkov, N. A., Pickering, K. E., Kowalewski, M., and Wang, J.: The GeoTASO airborne spectrometer project, Earth Observing Systems XIX, Proc. SPIE, 9218, 92181H-92181H-9, doi:10.1117/12.2063763, 2014.

Lin, J.-T., Martin, R. V., Boersma, K. F., Sneep, M., Stammes, P., Spurr, R., Wang, P., Van Roozendael, M., Clémer, K., and Irie, H.: Retrieving tropospheric nitrogen dioxide from the Ozone Monitoring Instrument: effects of aerosols, surface reflectance anisotropy, and vertical profile of nitrogen dioxide, Atmos. Chem. Phys., 14, 1441-1461, doi:10.5194/acp-14-1441-2014, 2014.

Liu, C., Liu, X., Kowalewski, M. G., Janz, S. J., González Abad, G., Pickering, K. E., Chance, K., and Lamsal, L. N.: Characterization and verification of ACAM slit functions for trace-gas retrievals during the 2011 DISCOVER-AQ flight campaign, Atmos. Meas. Tech., 8, 751-759, doi:10.5194/amt-8-751-2015, 2015.

Liu, X., Chance, K., Sioris, C. E., Spurr, R. J. D., Kurosu, T. P., Martin, R. V., and Newchurch, M. J.: Ozone profile and tropospheric ozone retrievals from the global ozone monitoring experiment: algorithm description and validation, J. Geophys. Res.-Atmos., 110, D20307, doi:10.1029/2005JD006240, 2005.

Liu, X., Bhartia, P. K., Chance, K., Spurr, R. J. D., and Kurosu, T. P.: Ozone profile retrievals from the Ozone Monitoring Instrument, Atmos. Chem. Phys., 10, 2521-2537, doi:10.5194/acp-10-25212010, 2010.

Loughner, C. P., Allen, D. J., Pickering, K. E., Zhang, D.-L., Shou, Y.-X., and Dickerson, R. R.: Impact of fair-weather cumulus clouds and the Chesapeake Bay breeze on pollutant transport and transformation, Atmos. Environ., 45, 4060-4072, doi:10.1016/j.atmosenv.2011.04.003, 2011.

Martin, R. V., Chance, K., Jacob, D. J., Kurosu, T. P., Spurr, R. J., Bucsela, E., Gleason, J. F., Palmer, P. I., Bey, I., Fiore, A. M., Li, Q., Yantosca, R. M., and Koelemeijer, R. B. A.: An improved retrieval of tropospheric nitrogen dioxide from GOME, J. Geophys. Res.-Atmos., 107, ACH-9, doi:10.1029/2001JD001027, 2002.

McLinden, C. A., Olsen, S. C., Hannegan, B., Wild, O., Prather, M. J., and Sundet, J.: Stratospheric ozone in 3-D models: A simple chemistry and the cross-tropopause flux, J. Geophys. Res.-Atmos., 105, 14653-14665, 2000.

McLinden, C. A., Fioletov, V., Boersma, K. F., Kharol, S. K., Krotkov, N., Lamsal, L., Makar, P. A., Martin, R. V., Veefkind, J. P., and Yang, K.: Improved satellite retrievals of $\mathrm{NO}_{2}$ and $\mathrm{SO}_{2}$ over the Canadian oil sands and comparisons with surface measurements, Atmos. Chem. Phys., 14, 3637-3656, doi:10.5194/acp-14-3637-2014, 2014.

Munro, R., Lang, R., Klaes, D., Poli, G., Retscher, C., Lindstrot, R., Huckle, R., Lacan, A., Grzegorski, M., Holdak, A., Kokhanovsky, A., Livschitz, J., and Eisinger, M.: The GOME2 instrument on the Metop series of satellites: instrument design, calibration, and level 1 data processing - an overview, Atmos. Meas. Tech., 9, 1279-1301, doi:10.5194/amt-9-1279-2016, 2016.

Nowlan, C. R., Liu, X., Chance, K., Cai, Z., Kurosu, T. P., Lee, C., and Martin, R. V.: Retrievals of sulfur dioxide from the global 
ozone monitoring experiment 2 (GOME-2) using an optimal estimation approach: algorithm and initial validation, J. Geophys. Res.-Atmos., 116, D18301, doi:10.1029/2011JD015808, 2011.

Nowlan, C. R., Martin, R. V., Philip, S., Lamsal, L. N., Krotkov, N. A., Marais, E. A., Wang, S., and Zhang, Q.: Global dry deposition of nitrogen dioxide and sulfur dioxide inferred from space-based measurements, Global Biogeochem. Cy., 28, 1025-1043, doi:10.1002/2014GB004805, 2014.

Otte, T. L. and Pleim, J. E.: The Meteorology-Chemistry Interface Processor (MCIP) for the CMAQ modeling system: updates through MCIPv3.4.1, Geosci. Model Dev., 3, 243-256, doi:10.5194/gmd-3-243-2010, 2010.

Palmer, P. I., Jacob, D. J., Chance, K., Martin, R. V., Spurr, R. J., Kurosu, T. P., Bey, I., Yantosca, R., Fiore, A., and Li, Q.: Air mass factor formulation for spectroscopic measurements from satellites: application to formaldehyde retrievals from the global ozone monitoring experiment, J. Geophys. Res.-Atmos., 106, 14539-14550, doi:10.1029/2000JD900772, 2001.

Popp, C., Brunner, D., Damm, A., Van Roozendael, M., Fayt, C., and Buchmann, B.: High-resolution $\mathrm{NO}_{2}$ remote sensing from the Airborne Prism EXperiment (APEX) imaging spectrometer, Atmos. Meas. Tech., 5, 2211-2225, doi:10.5194/amt-5-22112012, 2012.

Prather, M.: Catastrophic loss of stratospheric ozone in dense volcanic clouds, J. Geophys. Res.-Atmos., 97, 10187-10191, 1992.

Richter, A., Begoin, M., Hilboll, A., and Burrows, J. P.: An improved $\mathrm{NO}_{2}$ retrieval for the GOME-2 satellite instrument, Atmos. Meas. Tech., 4, 1147-1159, doi:10.5194/amt-4-1147-2011, 2011.

Román, M. O., Gatebe, C. K., Schaaf, C. B., Poudyal, R., Wang, Z., and King, M. D.: Variability in surface BRDF at different spatial scales $(30 \mathrm{~m}-500 \mathrm{~m})$ over a mixed agricultural landscape as retrieved from airborne and satellite spectral measurements, Remote Sens. Environ., 115, 2184-2203, doi:10.1016/j.rse.2011.04.012, 2011.

Rothman, L., Gordon, I., Babikov, Y., Barbe, A., Chris Benner, D., Bernath, P., Birk, M., Bizzocchi, L., Boudon, V., Brown, L., Campargue, A., Chance, K., Cohen, E. A., Coudert, L., Devi, V., Drouin, B. J., Fayt, A., Flaud, J.M., Gamache, R., Harrison, J., Hartmann, J.-M., Hill, C., Hodges, J., Jacquemart, D., Jolly, A., Lamouroux, J., Le Roy, R., Li, G., Long, D., Lyulin, O., Mackie, C., Massie, S., Mikhailenko, S., Müller, H., Naumenko, O., Nikitin, A., Orphal, J., Perevalov, V., Perrin, A., Polovtseva, E., Richard, C., Smith, M., Starikova, E., Sung, K., Tashkun, S., Tennyson, J., Toon, G., Tyuterev, V., and Wagner, G.: The HITRAN 2012 molecular spectroscopic database, J. Quant. Spectrosc. Ra., 130, 4-50, doi:10.1016/j.jqsrt.2013.07.002, 2013.
Sather, M. E. and Cavender, K.: Update of long-term trends analysis of ambient 8 hour ozone and precursor monitoring data in the South Central US, encouraging news, J. Environ. Monitor., 14, 666-676, doi:10.1039/C2EM10862C, 2012.

Schaaf, C. B., Gao, F., Strahler, A. H., Lucht, W., Li, X., Tsang, T., Strugnell, N. C., Zhang, X., Jin, Y., Muller, J.-P., Lewis, P., Barnsley, M., Hobson, P., Disney, M., Roberts, G., Dunderdale, M., Doll, C., d'Entremont, R. P. Hu, B., Liang, S., Privette, J. L., and Roy, D.: First operational BRDF, albedo nadir reflectance products from MODIS, Remote Sens. Environ., 83, 135-148, doi:10.1016/S0034-4257(02)00091-3, 2002.

Schönhardt, A., Altube, P., Gerilowski, K., Krautwurst, S., Hartmann, J., Meier, A. C., Richter, A., and Burrows, J. P.: A wide field-of-view imaging DOAS instrument for two-dimensional trace gas mapping from aircraft, Atmos. Meas. Tech., 8, 51135131, doi:10.5194/amt-8-5113-2015, 2015.

Skamarock, W. C., Klemp, J. B., Dudhia, J., Gill, D. O., Barker, D. L., Duda, M. G., Huang, X.-Y., Wang, W., and Powers, J. G.: A description of the Advanced Research WRF version 3, Tech. Rep. NCAR/TN-475+STR, NCAR, Boulder, CO, USA, 2008.

Spurr, R. J. D.: VLIDORT: A linearized pseudo-spherical vector discrete ordinate radiative transfer code for forward model and retrieval studies in multilayer multiple scattering media, J. Quant. Spectrosc. Ra., 102, 316-342, doi:10.1016/j.jqsrt.2006.05.005, 2006.

Thalman, R. and Volkamer, R.: Temperature dependent absorption cross-sections of $\mathrm{O}_{2}-\mathrm{O}_{2}$ collision pairs between 340 and $630 \mathrm{~nm}$ and at atmospherically relevant pressure, Phys. Chem. Chem. Phys., 15, 15371-15381, doi:10.1039/c3cp50968k, 2013.

Vandaele, A. C., Hermans, C., Simon, P. C., Carleer, M., Colin, R., Fally, S., Mérienne, M. F., Jenouvrier, A., and Coquart, B.: Measurements of the $\mathrm{NO}_{2}$ absorption cross-section from 42000 to $10000 \mathrm{~cm}^{-1}(238-1000 \mathrm{~nm})$ at 220 and $294 \mathrm{~K}$, J. Quant. Spectrosc. Ra., 59, 171-184, 1998. 